\title{
Los tratados de arquitectura militar publicados en España durante el reinado de Carlos III.
}

\author{
José Enrique Garcia Melero
}

"Es la Milicia herencia de los Nobles: pues desde que se conoce el Arte de ella, ha estado vinculada à los mas ilustres personajes. Si recurrimos à los primeros tiempos en que se descubren los fundamentos de este Arte, la

hallamos cultivada de los Dioses, i Heroes de la Gentilidad. Los Gigantes monstruosos hijos de la tierra, intentaron desposeer del sagrado dominio del cielo à los

Dioses. I declarando guerra al mismo Firmamento, pretendieron escalarle, uniendo para esto la horrorosa máquina de los más encumbrados montes. Sintieron los

Dioses el assalto, è indignados de la Sacrilega temerosidad, les fue preciso valerse de su esfuerzo, i rebatir la guerra con la guerra: siendo en ella promiscuamente ia Capitanes, ia Soldados" (sic.). (Vicente

Garcia de la Huerta, "Bibliotheca Militar Española". Madrid, 1760, págs. 1-2).

Los tratados de fortificación desempeñaron durante el reinado de Carlos III un papel fundamental, tal y como venía sucediendo desde el siglo XVI, tanto en la enseñanza de los ingenieros militares en su calidad de cuerpo de élite especializado en este tipo de construcciones como en la instrucción de los oficiales del ejército en general, cuya misión era la de ocuparse al mismo tiempo de la defensa y del ataque de las plazas fuertes. Estos libros fueron un instrumento didáctico totalmente imprescindible, que cumplia una doble función, teórica y práctica, proporcionando nociones, principios y sistemas sobre esta compleja especialidad arqui- 
tectónica, intimamente relacionada con la civil y la hidráulica. Instruian de un modo conjunto o por separado en la realización de las fortificaciones permanentes y en las de campaña, la castramentación, aspecto quizás más relacionado con la actividad de los mandos del ejército que con la labor de los ingenieros militares, dada, además, la falta de un número suficiente de tales especialistas en los campos de combate?

Estos tratados, basados en unos conocimientos más o menos profundos de las matemáticas y de la geometria, disciplinas que muchas veces suelen introducir a esos libros como primer paso ineludible, cumplian una finalidad eminentemente práctica, aunque proporcionaban partes teóricas desigualmente extensas. En ellos la arquitectura está al servicio de la estrategia militar, dependiendo su realización en gran medida de los avances experimentados por la tecnología armamentística. Pero el grueso de estos textos incluye una serie de ejemplos prácticos y de problemas relacionados con la forma de trazar las distintas lineas de las fortificaciones según los diferentes sistemas defensivos ideados por los ingenieros militares a lo largo de la Historia. Las ilustraciones, que suelen ser bastante semejantes en todos ellos, servian para visualizar y hacer más comprensible toda esa teoria, aportando modelos siempre reproducibles tanto de las fortificaciones, en general, como de cada una de sus partes, en particular, y de cuarteles, hospitales, puentes, atrincheramientos...

La ingenieria militar española anterior a Carlos III contaba en este campo de la fortificación con importantes antecedentes bibliográficos desde que a finales del siglo XVI Cristóbal de Rojas publicó en Madrid su famosa Teórica y práctica de la fortificación para que sirviera a la madrileña Academia de Matemáticas, fundada en 1583 por Felipe II y que

1 Una relación comentada de los tratados de fortificación aparecidos en España hasta 1880 la ofrecimos en: Bonet Correa, A., dr., Garcia Melero, J. E., Dieguez, S. y Lorenzo. S. Bibliografia de Arquitectura. Ingenieria y Urbanismo en España (1498 -1880). Madrid - Vaduz, Turner Libros - Topos Verlag, (1980). 2 vol. Obra fundamental es el repertorio: Almirante, J., Bibliografia Militar de España. Madrid, Imp. Manuel Tello, 1876. B. N.: Ct. 649. Las fuentes bibliográficas sobre esta materia aparecidas antes de la llustración fueron recopiladas por: GARCIA DE LA HUERTA, V., Bibliotheca Militar Española. Madrid, Antonio Pérez Soto, Impressor de los Reynos, y de las Reales Academias Española, y de la Historia, año MDCCLX (1760). B. N.: 2/62, 355. Veáse tambien el cap. X. págs. 217-254, en especial págs. 231-254, de: Capel, H., Sanchez, J. E., y Moncada, O.. De Palas a Minerva. La formación cientifica y la estructura institucional de los ingenieros militares en el siglo xvil. (Barcelona-Madrid), Serbal - CSIC., 1988. Más recientemente: GARCIA MELERO, J. E.: "LOS tratados de Fortificación militar en España (1788-1833)". Ponencia presentada en las Primeras Jornadas de Ingenieria Militar. Cádiz, noviembre de 1989. En prensa: Cadiz, Delegación de Cultura de la Junta de Andalucia - Fundación Rafael Alberti- Centro Asociado a la UNED., de Cádiz. 


\section{Siegistrudo $\mathrm{C}$. $930 \%$ $T R A T A D O$}

9

D $\mathbf{E}$

FORTIFICACION,

Arte de conftruir los Edificios Militares, y Civiles.

Escrito Ex INGLEs,

POR. JUAN MULLER.

TRADUCIDO EN CASTELLANO, DTridrDo Ė DOS TOMON;

Y AUMENTADO CON NOTAS, ADICIONES,

Y 22. Laminas finas fobre las 26 ., que ilutran al Original,

POR D. MIGUEL SANCHEZ TARAMAS,

Capitan de Iafanteria, ed Ingeniero Ordinario de los Exercitos de S. M., aetualmenté empleado en la enfefianza de

la Keal Academia Militar de Mathematicas

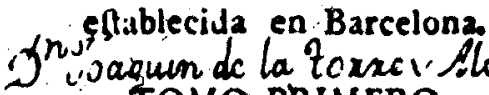

TOMO PRIMERO.

CON SUPEHIOR PERMISO.
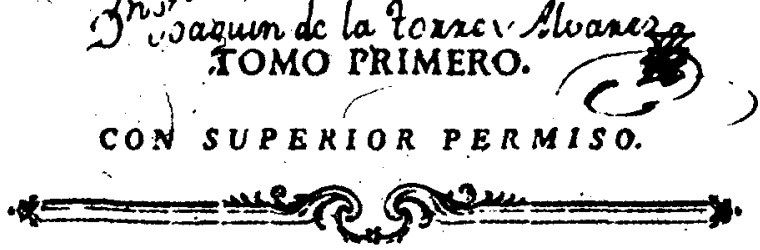

Burcelgnal: Por THONIAS PIFERRER Imprefor del Ráy' nueffro Señor, Plaza del Angül. Año izég.

Lámina 1. Portada de la edición española del Tratado de fortificación de John Muller, impresa en Barcelona por Thomás Piferrer en 1769 y traducido y aumentado por Miguel Sánchez Taramas. 
contó entre sus primeros directores con personalidades tan importantes como Juan de Herrera, Francisco de Mora y Juan Gómez de Mora ${ }^{2}$. Pero en los últimos años de la centuria del barroco y primeras décadas de la de la llustración Sebastián Fernández de Medrano, profesor de la Academia Militar de Bruselas, dio a la imprenta una serie de obras útiles para la formación del ingeniero o arquitecto militar, en las que se ocupó tanto de la fortificación regular como de la irregular, y del ataque y defensa de las plazas. Su tratado más importante fue el titulado El Architecto Perfecto en el Arte Militar, que conoció las ediciones de 1700,1708 y $1735^{3}$. En este libro -auténtica síntesis de otras publicaciones del que fuera profesor de la Academia Militar de Bruselas e inspirador de la organización y del plan de estudios de la Academia de Matemáticas de Barcelona, creada en 1699abordó, además de los temas antes indicados, una serie de aspectos arquitectónicos importantes, como lo eran la fabricación de cuarteles, almacenes a pruebas de bombas, murallas, dando unas nociones de geometria, trigonometria, cálculo y regla de proporción.

Se reflejan en estos tratados de fortificación aparecidos en España entre 1759 y 1788 una serie de factores que, quizás un poco tópicamente pero con cierio fundamento, siempre han caracterizado a la llustración española y, de una manera más concreta, al reinado de Carlos III: la reforma militar, la política cultural francófila, la obsesión pedagógica, el pragmatismo... Pero, aunque todas estas notas quizás sirvan para delimitar su filiación ilustrada, más epidérmica que de contenido, no están exentas de una herencia barroca, pues persisten con bastante fuerza los

Rojas, C., Compendio y Breve Resolucion de Fortificación, conforme a los tiempos presentes... Por el Capitan.... Ingeniero Militar de su Magestad... En Madrid, por Juan de Herrera, Año 1613.

3. Fernandez de Medrano. S., El Architecto Perfecto en el Arte Militar... En Brusselas, en Casa de Lamberto Marchant, Mercader de Libros al Buen Pastor, 1700. B. N.: 3/74, 348 y $2 / 15,170$. Este libro se reeditó en Amberes, por Henrico y Cornelio Verdussen. 1708. B. N.: R. $/ 14,593,2 / 16.385$ y 3/47, 299. Otra edición en: Amberes, por la viuda de Henrico Verdussen, en 1735. Fernández de Medrano, quien habia llegado a Flandes en 1668 como Alférez de un tercio, fue protesor de ingenieria, artilleria, arquitectura militar, geometria práctica y geografia en la Academia Militar de Bruselas. Felipe $V$ le llamó hacia 1702 a España para que elaborara el plan de estudios de la Academia de Matemáticas de Barcelona. Sus libros sirvieron de textos en la Academia Militar de Bruselas, reimprimiéndose algunos de ellos para que fueran empleados en esta nueva Escuela española. Otras obras suyas son: L'Ingenieur ou l'Architecture Militaire. Brusselles, chez Lambert Marchant, 1696. (Reimpreso en 1709, 1790 y 1796). Breve tratado del ataque y defensa de una Plaza Real. Brusselas, Lamberto Marchant, 1698? Geographia o moderna descripción del Mundo y sus partes. Brusselas, 1686. Los seis primeros libros, onze y doce de los Elementos Geométricos del famoso philosopho Euclides Megarense. Ampliado de nuevas demostraciones. Bruselas, 1701 y El perfecto artificial bombardero y artillero. Amberes, 1708 
sistemas de fortificación del siglo XVII y de la primera mitad del XVIII. Son textos que en gran medida están bajo la influencia y son deudores de los métodos del Mariscal Vauban -algunos de cuyos escritos y experiencias son publicados ahora como parte integrante o apéndice de estos libros-, de Marolois, del Conde de Pagan, de Landau y del holandés barón de Coehorn.

\section{POLITICA DE TRADUCCIONES, Y REACCIÓN Y TRADICIÓN HISPÁNICA}

Durante el reinado de Carlos III se siguió una política de traducciones de obras extranjeras con la idea de internacionalizar y de actualizar los conocimientos sobre fortificaciones de los ingenieros militares y de los oficiales del ejército español. Esta directriz fue en gran medida promovida por el célebre conde O'Reilly, inspector general de Infanteria, a quien se debe el encargo de vertir al castellano varios libros de Le Blond tratando
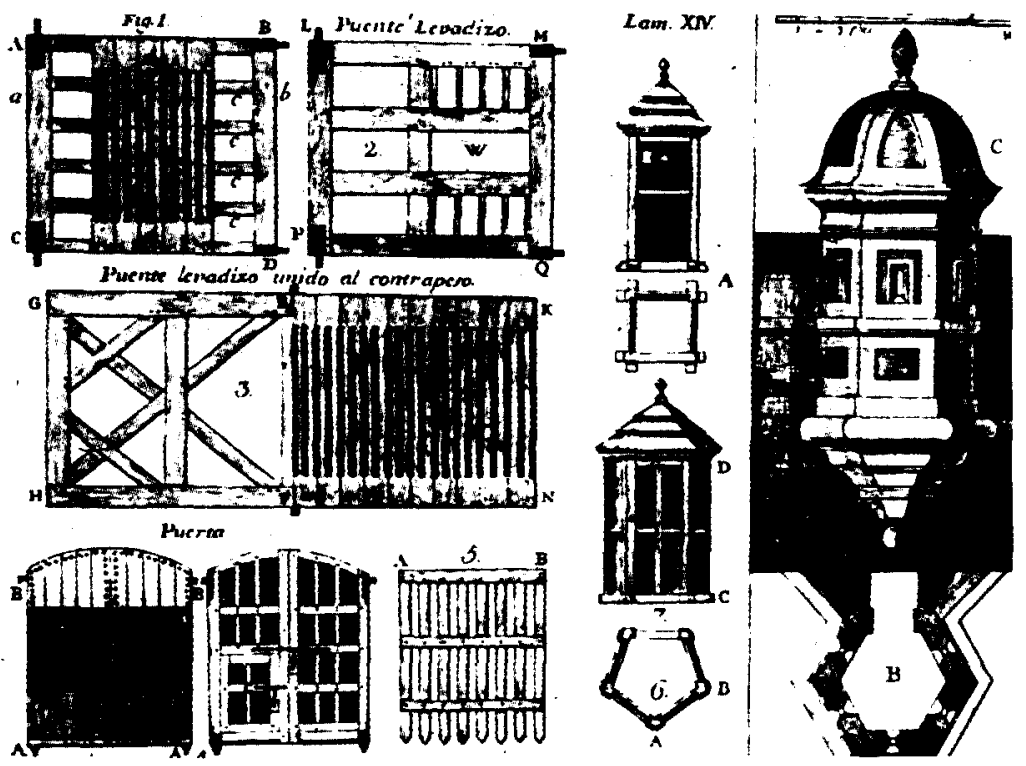

Lamina 2. Lamina XIV del Tratado de fortificacion de Muller, en el que se representan un puente levadizo, una puerta y garitas. Grabado de Pauner. 
de fomentar más el estudio del arte de la guerra ${ }^{4}$. Asi, se tradujeron textos franceses como la Ciencia de Puestos Militares, o Tratado de las Fortificaciones de Campaña de Jean Louis Le Cointe, publicado en Valencia en $1770^{5}$, el Arte de la guerra del Marqués de Quincy en $1772^{6}$ y los libros del ya citado Guillaume Le Blond titulados Tratado del ataque de las Plazas ${ }^{7}$; Tratado de defensa de las Plazas ${ }^{8}$, ambas de 1777, y Elementos de fortificación ${ }^{9}$ de un año antes, que fueron reeditados ya en

En la introducción «Al lector», pág. Ill, del traductor al español de los Elementos de fortificación de LE-BLOND (Madrid. 1776) se agradecia: "el infatigable esmero con que el Excmo. Señor Conde de O'Reilly procura fomentar el estudio del arte de la guerra, siendo éste uno de los objetivos en que S. E. ha puesto la mayor atencion como el mas digno de su ministerio, y el más importante al lustre y ventajas de la profesión militar". El inspector general de Infanteria también promovió la traducción del Tratado del ataque de las Plazas y del Tratado de defensa de las plazas, ambos libros publicados en Madrid en 1777.

${ }^{5}$ Le CONTE, (J. L.). Ciencia de Puestos Militares. O Tratado de las Fortificaciones de Campaña, para uso de los Oficiales de Infanteria destacados en tiempos de Guerra: en que se enseñan el modo de atacar. y defender un Puesto. Escrita en francés por el Sr. .... Teniente que fue de Infanteria, y Capitán de Cavalleria: de la Academia Real de Nimes. Traducida en Español para la instrucción de los Cavalleros Cadetes del Regimiento Inmemorial del Rey, por D. Joseph Caamaño, y Gayoso, Capitán del mismo Regimiento... En Valencia. por Benito Monfort, año 1770. 12 hoj., 215 págs. con X láms. B. N.: 2/27, 832.

${ }^{6}$ [SEVIN DE QUINCY, Charles]. Arte de la guerra. o maximas, é instrucciones del arte militar. escrito en francés por el Marqués de Quincy. Teniente General de Artilleria. Aumentado con un tratado de Minas, y Tablas para las provisiones de las Plazas de Guerra. Escrito en el mismo idioma por el Mariscal de Vauvan, y traducido al castellano por Don Raymundo Ortiz de Zárate, Subteniente del Regimiento de Cantabria... En Madrid, en la Imprenta de Pedro Marin (s.a.: 1772) 2 vol. Contienen: Vol. I: 6 hoj., 304 págs. con 4 fols. plegs. -Vol. Il: 4 hoj.. 158 págs., con 13 esquemas plegs. y 2 lams. plegs. B. N.: 3/43. 909-10.

LE-BLond, G(uillaume). Tratado del ataque de las Plazas. Traducido al castellano sobre la segunda edición. que escribió en francés El Abate.... Maestro de Matemáticas del Serenisimo Señor Delfin, y de los Señores Condes de Provenza y de Artois, \&c. Madrid. por D. Joachín Ibarra Impresor de Cámara de S. M., MDCCLXXVII (1777). 2 hojs., XXXVI, 364 pags., con XVIII lams. B. N.: 2/16, 837.

${ }^{8}$ LE-Blond, G(uillaume). Tratado de defensa de las plazas, con varias observaciones útiles para proceder à su reconocimiento; y un breve compendio de los principios mas generales. que puedan contribuir á que se establezcan ventajosamente los quarteles de Invierno. Traducida sobre la segunda edición, que escribió en Francés El Abate Le Bond. Maestro de Matemáticas del Serenísimo Delfin y de los Señores Condes de Provenza y de Artois \&c. Madrid, por Joachin Ibarra Impresor de Camara de S. M., MDCCLXXVII (1777). 2 hojs., XX, 259 págs., 1 hoj. pleg. de tablas. $V$ láms. plegs. B. N.: 3/46, 425.

Le-Blond, G(uillaume), Elementos de fortificacion, en que se explican los principios, y métodos de delinear las obras de la fortificación regular é irregular, los sistemas de los más célebres Ingenieros \&c. Traducidos al castellano sobre la sexta edición que escribió en francés el Señor Le-Blond, maestro de Matemáticas del Señor Delfin, $y$ de los Señores Condes de Provenza, y de Artois, \&c. Madrid, por Joachin Ibarra, 1776. XXXII hojs., 382 págs., 22 lams. B. N.: 3/46, 665 y 7/32, 329. Este libro ya era conocido en España bajo el título de Ciencia de Militares, que contiene unos breves principios de Geometria, para ia perfecta inteligencia de la Fortificación; con utilisimo Tratado de este Arte, en lo regular e irregular, que en idioma francés dio a la luz Mms. Le Blond, etc... En Cádiz, por Don Manuel Espinosa de los Monteros, Impresor Real de la Marina, 1757 
$1805^{10}$. Pero en 1769 ya se había vertido al español de la edición inglesa de 1755 el Tratado de fortificación de Juan Muller, autor de varias obras sobre esta ciencia, las matemáticas y la artilleria ${ }^{11}$. Así, se diseño, quizás conscientemente, un programa didáctico bastante completo con la traducción de una serie de textos - salidos a la luz en Francia e Inglaterra, las dos primeras potencias militares europeas de la época- complementarios entre si, que servirian de corpus teórico al mismo tiempo básico y especializado para la formación de los militares. Comprendía desde la fortificación permanente a la de campana. el ataque y la defensa de las plazas, construcción de edificios militares y elementos de matemáticas y geometria. Este diseño pedagógico del reinado de Carlos III pervivió durante el de su sucesor Carlos IV, ya que entonces apenas se publicó algún libro relacionado con la fortificación, quedando inéditos varios manuscritos.

La política de traducciones de estos textos extranjeros obedecia, además de a las ideas de internacionalizar y de actualizar los tratados españoles acomodándolos a los nuevos tiempos, tal y como antes ya se ha indicado, a un cierto complejo de inferioridad y de incapacidad de nuestros ingenieros y militares. Así lo confesó precisamente, y con toda honestidad, persona tan competente como el mismo Sánchez Taramas en su prólogo a la obra de Muller al considerarse insuficiente para redactar alguna obra nueva, que fuese de la apetecida utilidad; y debido a ello resolvió "aprovecharse de las ajenas" ${ }^{12}$. Este fue el motivo por el cual

${ }^{10}$ LE-Blond, G(uillaume). Elementos de fortificación.. Madrid, por Gómez Fuentenebro y Compania, 1805. XXXIII, 382 págs., con 22 láms. B. N.: 1/36, 735.

Muller, J., Tratado de Fortificación ó Arte de construir los Edificios Militares, y Civiles. Escrito en inglés, por... Traducido al castellano, dividido en dos tomos, y aumentado con notas. adiciones, y 22 láminas finas sobre las 26, que ilustran al Original, por D. Miguel Sánchez Taramas... Barcelona, por Thomas Piferrer Impresor del Rey nuestro Señor. Plaza del Angel, año 1769. 2 vol., lám. pleg., $21 \mathrm{~cm}$. B. N.: 3/45,242-3. Contiene: Vol. I: 24 hojs., 430 págs., con XXIII láms. plegs.-Vol. It: 4 hojs., 356 págs., 22 lams. Tambien: MULLER, John, $A$ treatise containing the elementary part of fortification, Regular and Irregular. With remarks on the constructions of the most celebrated Authors, particularly of Marshal de Vauban and Barm Coehorn, in which the Pertection and imperfection of their general works are confidered. For the use of the Royal Academy of Artillery at Woolwich. Illustrated with thirty-four copper plates. By John Muller, Professor of Artillery and Fortification. London, printed for J. Nourse, at the Lamb, opposite Katherine-Street, in the Strand, MDCCXLVI (1746). XVI, 232 págs. Algunas láminas estan dibujadas por el propio Mulier y grabadas por J. Mynde.

${ }_{12}$ MULleR, J., obra citada en nota 11. En la dedicatoria de Miguel Sanchez Taramas a J. Martin Cermeño se dice: "Ocupada mi imaginación con esta importante idea, y llevado de mi genio laborioso. al propio tiempo que estoy persuadido de mi insuficiencia para formar alguna obra. que fuese de la apetecida utilidad; resolvi aprovecharme de las agenas, y no dexar ociosos. ni los pocos ratos que më flanquea mi destino a la enseñanza en esta Real Academia, ni el ansia de concurrir en quanto pueda con mi aplicación al bien de la Patria". 
tradujo al español ese tratado inglés. Tal complejo - que quizás se debiera a las contínuas derrotas militares españolas, que habian ocasionado la pérdida de gran parte del Imperio - también seguiría presente, en 1772, ahora en Raimundo Ortiz de Zárate, quien al dedicar el Arte de la guerra del Marqués de Quincy al Conde de O'Reilly afirmó que su traducción era una consecuencia de no encontrarse "con suficiente pericia Militar para formar con propiedad una Obra original de esta clase ${ }^{13}$.

El mismo Sánchez Taramas trató de incorporar al texto de Muller una serie de modelos de arquitecturas militares españolas en un afán de proporcionar un cierto aire español al libro y de dar a conocer lo que se hacia en España en este campo. Reprodujo, por ejemplo, planos y alzados de cuarteles, como el proyectado en 1751 por Juan Martín Cermeño en Reus (Tarragona) para alojar un Escuadrón de Caballería o Dragones, admitiendo en cierta forma su comparación con los que se construian ordinariamente en Inglaterra, proporcionados por Muller. También publicó grabados del cuartel de infantería de la Barceloneta. Precisamente esta edición española se la había dedicado a Martín Cermeño, entonces Teniente General de los Reales Ejércitos e Ingeniero General. Las notas de Sánchez Taramas y las nuevas ilustraciones incorporadas en la edición española mejoraron, sin duda, considerablemente el texto del original inglés.
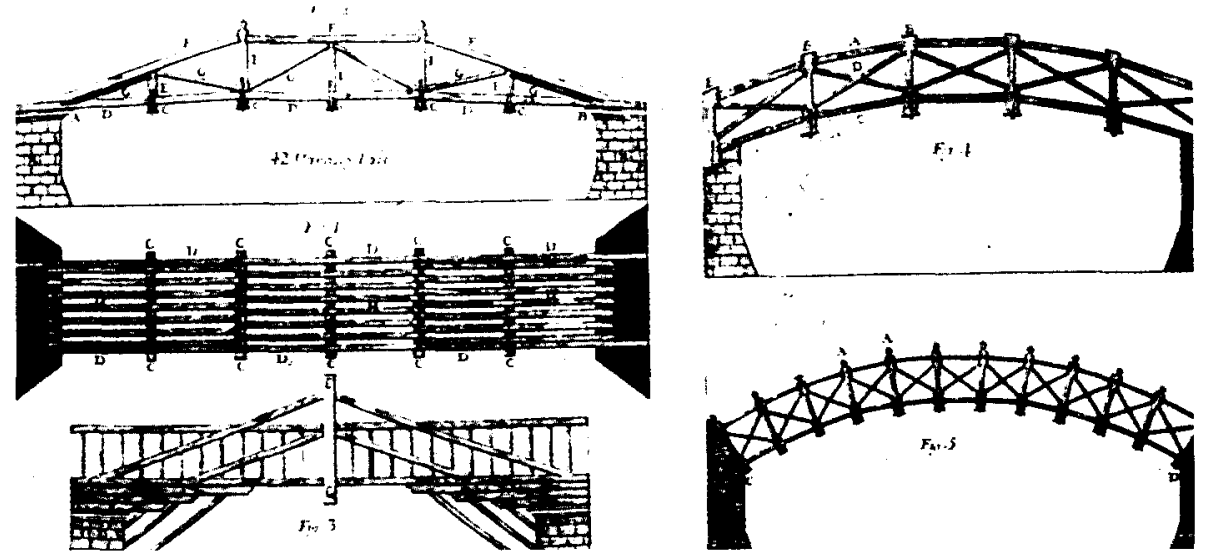

Lamina 3. Lamina 1A del Tratado de fortificacion de Muller, añadida por Miguel Sánchez Taramas a la edición española de 1769, grabada por Pauner, en la que se representan puentes de madera, basandose en Palladio.

${ }^{13}$ SeVIn de Quincy, Ch., obra citada en nota 6. fol. 3 anverso. 
Tales obras extranjeras, la mayoría de ellas de bastante calidad, hacian prácticamente innecesarias las redacciones de textos propios. Pero no por ello se abandonó la idea de publicar tratados escritos por autores españoles, aunque tan sólo salieran a luz dos durante este reinado y prácticamente ninguno en el de Carlos IV. El más significativo fue el de Pedro de Lucuce, titulado Principios de fortificación, impreso en $1775^{14}$, ya que las Nociones militares de José Ignacio March es, en realidad, un supiemento del libro anterior, al que trataba de completar ${ }^{15}$.

La obra de Lucuce era en cierta forma una sintesis de diversos tratados, cuyos contenidos habia escogido, resumido y ordenado con la idea de conseguir un texto breve y conciso que aportara definiciones claras e inteligibles para cualquier persona ${ }^{16}$. Sin embargo, su libro entrañaba en algo la reinvindicación de los antiguos escritores españoles frente a la política de traducciones. En este sentido los Principios de fortificación están en la misma línea tradicional y nacionalista que Vicente García de la Huerta habia promovido en su Biblioteca Militar Española de 1760, tratando de demostrar la existencia de una numerosa e importante bibliografia escrita por autores españoles ${ }^{17}$. Asi, Lucuce recogió las ideas de este célebre escritor, autor de la Raquel, que recomendaba a las tropas que leyeran en su idioma, tanto por ser más inteligible que el extranjero como "porque es hacer injuria a la nación dejarse llevar de la preocupación común de tener por lo mejor a lo más extraño" ${ }^{18}$. No queria decir con ello que los soldados no leyeran los mejores textos extranjeros, si no aquellos que realmente fueran superiores a los nacionales o que ense-

14 Lucuze, P(edro). Principios de fortificacion, que contienen las definiciones de terminos principales de las obras de Plaza, y de Campana, con una idea de la conducta regularmente observada en el Ataque, y Defensa de las Fortalezas. Dispuesta para la instrucción de la juventud militar. Por D.... Mariscal de Campo de los Reales Exercitos. y Director de la Real Academia Militar de Mathematicas establecida en Barcelona... En Barcelona. por Thomas Piferrer Impresor del Rey Nuestro Senor, año 1772. 18 hojs., 318 págs., con X láms. pleg. $4{ }^{\circ}$ B. N. : 3/67. 691. 3/16.624, 3/44.364, 2/15.132 y 2/26.013.

is MARCH, J(oseph) I(gnacio), Nociones Militares, o suplemento a los principios de Fortificacion del Excmo. Senor Don Pedro de Lucuze, escrito para la instrucción de los Caballeros Cadetes del Regimiento de Dragones de Sagunto, por Don... Capitán del mismo Regimiento. Barcelona, por Bernardo Plá, Impresor, en los Algodonales. M.DCC.LXXXI (1781). 7 hojs., XXXV. 2 hojs., 391 pags. con VIll lams, plegs. B N. : 3/50, 059, 2/15.705. $2 / 17,230,2 / 25.340$ y $3 / 76,280$

11. LuCUCE. P., obra citada en nota 14 , fol. 5 anverso y reverso.

: GaRCIA de LA HUERTA. V.. Bibliotheca Militar Española. por D... Madrid. por Antonio Pérez de Soto. Impressor de los Reynos, y de las Reales Academias Española y de la Historia, año MDCCLX (1760). 3 hojs., 129 págs. B. N. : 2/62, 355.

${ }^{18}$ Garcia de la Huerta, V., obra citada, en nota 17, pag. 51. 
ñasen lo omitido por los españoles. A lo que añadió: "Opóngome sólamente al necio prurito de aquellos malos Patricios, que solo saben citar Autores peregrinos, no conociendo ni aún por el nombre los de su Nación. Puede el Soldado, y aún a mi parecer debe estudiar, y leer quantos libros de su facultad le vinieren a las manos, procurando siempre preferir los de su Nación. Y verdaderamente pienso, que en ninguna parte habrá más copia de Libros, y mejores, que en España, especialmente desde tiempos de Carlos Quinto, a Carlos segundo" "19.

No resulta, por consiguiente, extraño que Lucuce concediera una gran importancia a la bibliografía en su libro y que aconsejara la lectura de los antiguos escritores militares españoles a través del repertorio de Nicolás Antonio ${ }^{20}$ y del catálogo de Vicente García de la Huerta, al que se ha hecho referencia antes. También aludió a la obra titulada Escuela de Palas por contener la reseña de los mejores escritores de libros de fortificación ${ }^{21}$ y a Vicente de los Ríos, teniente de Artillería, y a su famosa Colección, impresa en Madrid en 1767, al tratar sobre la artillería ${ }^{22}$. Asi, a continuación de la nota preliminar al lector, Lucuce publicó el catálogo de algunos escritores militares, indicando su nombre, empleo, título de la obra, lugar y año de publicación, ordenando sus asientos cronológicamente desde el más antiguo al más moderno. Entre las obras más próximas a su tiempo citó a Ignacio Sala, teniente General e Ingeniero Director, y sus Reflexiones, y adiciones sobre la Defensa de las Plazas del Mariscal de Vauban, publicadas en Cádiz en $1747^{23}$ y a la obra aparecida en México en 1747 del Coronel e ingeniero jefe Phelipe Prosperi titulada La gran Defensa o Nuevo Sistema de Fortificación ${ }^{2.4}$.

19 Ibidem, págs. 51-53.

20 Nicolas, Antonio: Bilbiotheca Hispana "Nova". Roma. 1672. Bibliotheca Hispana “Vetus". Roma, 1696.

${ }^{21}$ [Chafrion, J(osé)], Escuela de Palas o Curso Mathematico dividido en XI Tratados.. Milan. en la Imp. Real por Marcos Antonio Pandulfo Malatesta, 1693. 2 vol. in fol.. B. N.: R./24.531, R./15,045 y R./6.360. Contiene: Vol. I: 20 hojs., 216 págs. 7 hojs., Vol. $11: 212$ págs.. 6 hojs., láms.

$?$ En la Biblioteca Nacional de Madrid se hallan las siguientes publicaciones de Rıs. Vicente de los. Discurso para la apertura de la Escuela Técnica de Artilleria, hecha en el Real Colegio militar de Segovia. Madrid, Joachin Ibarra. 1773. 8. N.: 2/155, 548 y 7/44,481, y Discurso sobre los ilustres autores e inventores de Artilleria. que han florecido en España. desde los Reyes Catolicos hasta el presente. Madrid, Joachin Ibarra, 1767. B. N. : 2/55,659.

23 Sin duda se debia referir al libro: LE PRESTE. S., Seigneur de Vauban. Tratado de la defensa de las plazas. que escribio Mr. de Vauban ... para la instruccion del Duque de Borgoña. Traducido por D. Ignacio Sala ... y aumentado con algunas reflexiones, y adiciones. Cádiz, por Pedro Gomez de Requena, 1743. 15 hoj.. 90 págs., VI lams. plegs. $20 \mathrm{cms}$. B. N.: R/35.637, 3/49.637 y 2/44,659.

24 Prosperi, F., La gran defensa. Nuevo método de fortificación, dividido en 3 ordenes, 

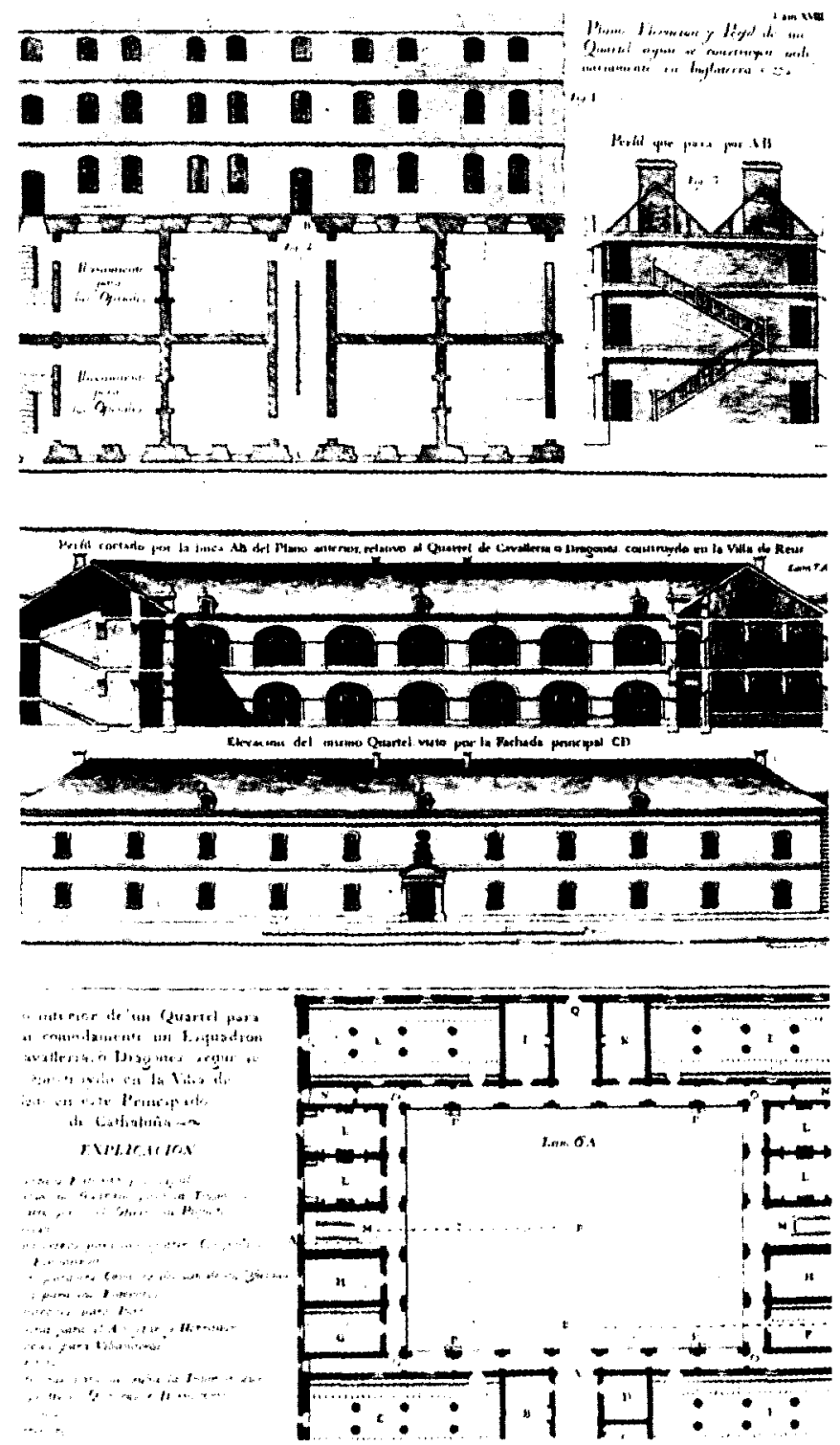

Lám 4. Láminas XVIII, $6 A$ y $7 A$ de la edición española del Tratado de fortificación de Mulier. En la lámina XVIII se representa el plano, elevación y perfil de un cuartel según se construian ordinariamente en Inglaterra. La lámina $6 \mathrm{~A}$ es el plano inferior de un cuartel para alojar un escuadrón de caballería o dragones según se halla construido en la villa de Reus (Tarragona). La lámina 7A representa el perfil y la elevación vista por la fachada principal de este mismo cuartel. 
Tal politica de traducciones transpasaria las fronteras del siglo XIX y en 1805 se reeditarian los Principios de Le-Blond y se vertirian al español la Instrucción dirigida a los oficiales de campana de Gaudi en $1806^{25}$ y los Elementos de fortificación de Noizet de Saint Paul en $1818^{26}$. Todo ello provocaria la crítica nacionalista de José Mariano Vallejo, quien en su Tratado Completo del arte militar de 1812 atribuyó la situación caotica de la ciencia militar en España a Godoy. Así afirmó en su libro refiriéndose a este valido lo siguiente: "Fomentando el partido de las traduccioncitas y elogios en los períodicos de quanto hacian nuestros vecinos, trató de poner á la nación en estado de creer que su felicidad dependía de su sumisión a la Francia, considerándose sin hombres instruidos, sin dinero, $\sin$ exército y $\sin$ ningún recurso para sostener su independencia»" ${ }^{27}$. Pero, a pesar de esta fiebre por lo hispánico tan románticamente decimonónica por su carácter nacionalista, hay que reconocer desde nuestra perspectiva histórica actual que esta política de traducciones de libros franceses era entonces totalmente oportuna. Se debía a la importancia que Francia había tenido, y aún en esa época poseía, como primera potencia militar en el siglo XVII y buena parte del XVIII, y a la existencia de un grupo bastante destacado de ingenieros militares teóricos tan sobresalientes como, por ejemplo, Errard de Bar-le-Duc, De Ville, Conde de Pagan, Vauban, Belidor y Le Blond.

En esta política de traducciones de textos útiles a los oficiales del ejército e ingenieros militares hubo un paralelismo entre sus escuelas $y$ la Real Academia de Bellas Artes de San Fernando, en donde también

a saber: doble, retozado y sencillo. México, Vda. de Joseph Bernardo de Hogal, 1744. con 73 láms. B. N.: 5/3,046 y 6-1/4.615.

${ }^{25}$ GaUDI. F. W. von. Instrucción dirigida à los oficiales de infanteria para trazar y construir toda suerte de obras de campana, y poner en estado de defensa los cementerios. iglesias. casas de campo. lugares. villas y ciudades. Escrita en alemán por .... General prusiano. Traducida al frances, y anotada por Monsieur Belaire. General de Division: y vertida de este idioma al Castellano. con aumento de notas, y un discurso preliminar. por * * . Madrid, en la Imprenta de don Tomás Alban, año de 1806. 251 págs., con 46 láms. plegs. $16.5 \mathrm{cms}$. B. N.; $1 / 71,215$ y 3/74,405. Edición alemana: 3/46,326.

26. Nolzet Saint Paul, Gaspar, Elementos de fortificacion. Escrito en frances por .... Coronel de ingenieros, y traducido al castellano para el uso de los caballeros cadetes del Regimiento real de zapadores-minadores-pontoneros. Madrid. en la Imprenta Real, año 1818. XIX hojs., 467 págs. En la biblioteca del Archivo Histórico Militar: E-7. ${ }^{\circ}-7$.

27 VALLEJO. José Mariano, Tratado complejo del arte militar. Tomo I: Que contiene la clasificación de todo lo que comprende la Ciencia de la Guerra, la Tabla Sinoptica, y todo lo que corresponde al Arte de fortificar. Escrito con aprobacion de S. M. por ... Mallorca. en la Imp. de Melchor Guasp, año de 1812. XIII hojs.. 136 pags con 13 lams. plegs. B. N.: R. 60,333 y 2/3,892. Vallejo también publicó unas Adiciones a la Geometria de don Benito Bails. Madrid. Hija de Ibarra, 1806. B. N.: 7/16, 950. Véase págs. III-IV del Tratado... 
se intentaba la publicación de textos propios al mismo tiempo que se echaba mano de lo foráneo ${ }^{28}$. Lo impreso por esa institución artística en el campo especifico de la arquitectura debió servir, asimismo, a los ingenieros militares, dados los nexos existentes entre muchas de sus realizaciones y las de los arquitectos. Pero en uno y otro caso se fracasó en gran medida al no pasarse, aunque su existencia siempre sea elogiable por poder seguirse a través de ellos el nivel intelectual de sus redactores, de simples manuscritos no divulgados por la imprenta y que, por lo tanto, incumplieron el fin perseguido con su realización: la difusión de unas ideas y de unos conocimientos, que tan sólo era posible lograr por medio de los libros. De esta forma tales textos inéditos tan sólo poseen un interés particular, individual, y así hay que considerarlos a la hora de estudiarlos en su justa medida y por su repercusión en la colectividad de arquitectos e ingenieros.

\section{LAS MATEMÁTICAS Y LA GEOMETRIA EN LOS TRATADOS DE FORTIFICACION}

No se puede concebir el estudio de la fortificación sin poseer antes unos buenos conocimientos de las Matemáticas y de la Geometria, totalmente imprescindibles para hacer los cálculos necesarios y trazar las lineas de las plazas fuertes. Por este motivo muchos de los tratados publicados en la época de Carlos III se inician con partes o capítulos dedicados a estas disciplinas, o presuponian una formación previa o cursada al mismo tiempo con el uso de otros textos especializados en ellas.

Asi, Lucuce comenzó sus Principios de fortificación con una introducción en la que se explicaban algunos términos de la Geometria. Pero esta parte fue considerada totalmente insuficiente por José María March, motivo por el cual publicó en 1781 sus Nociones militares, o suplemento a los principios de fortificación del Excmo. Sr. D. Pedro de Lucuce, siguiendo las disposiciones de las Reales Ordenanzas, que deseaban im.

${ }^{26}$ Marias. F. y Bustamante, A., "Sobre el "curso de arquitectura" de la Academia". El arte en tiempos de Carlos III. Madrid. Departamento de Historia del Arte "Diego Velazquez" del C.S.I.C., 1989. págs. 151-159. 

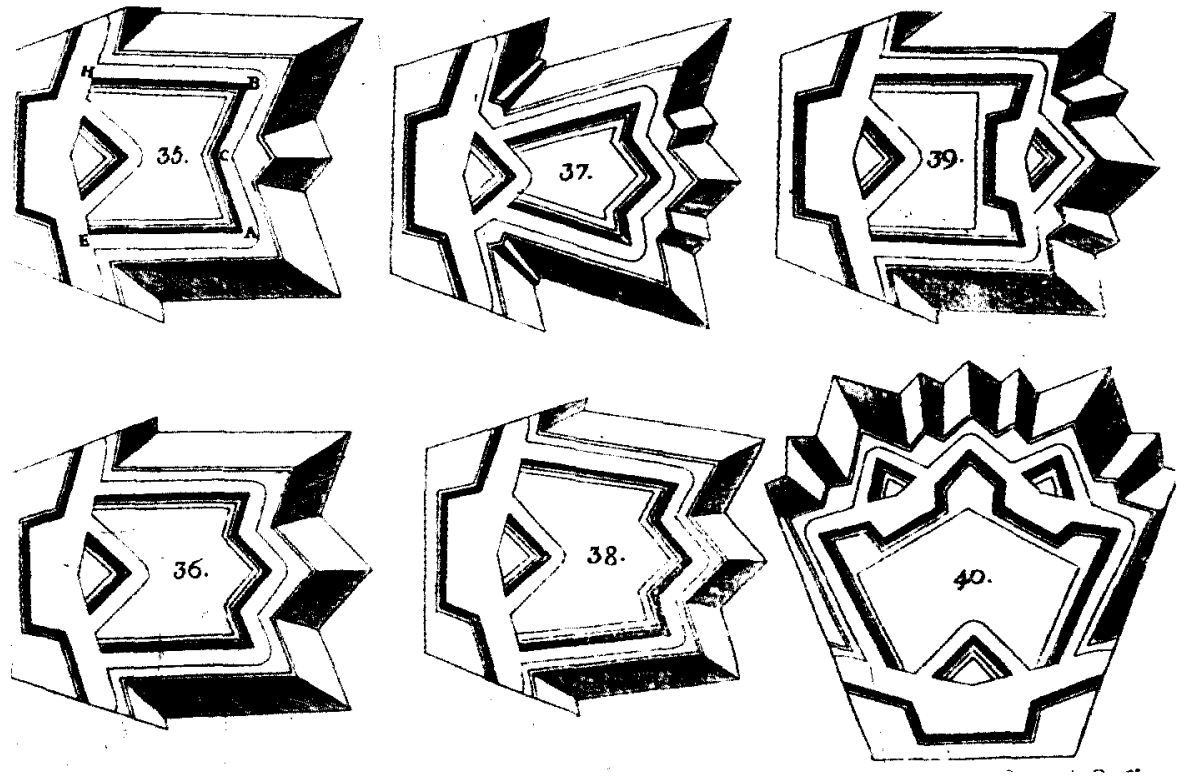

Lam 5. Lamina III de los Principios de fortificacion de Pedro de Lucuce, publicados en Barcelona en 1772 por Piferrer. Fig. 35: Tenaza simple. Fig. 36: Tenaza doble de las paralelas con un ángulo saliente en medio del frente y dos entrantes. Fig. 37: Tenaza doble a cola de golondrina. Fig. 38: Tenaza doble a contracola. Fig. 39: Hornabeque sencillo de las paralelas. Fig. 40: Corona u hornabeque doble. Los grabados son de Pauner.

poner a los cadetes en los conocimientos de la Aritmética y de la Geometría ${ }^{29}$. March consideraba que: "Las definiciones de Geometría insertas en el Tratado del Excelentísimo Señor Don Pedro de Lucuze (aunque buenas para entender, y distinguir las obras de fortificación) no suplian el Tratado de Geometria, que el cadete necesita para poder hacer sus aplicaciones á la Táctica, entender las demostraciones, que sobre este punto hacen los Autores Militares. y executar las operaciones geométricas que suele ofrecerse en Campaña. Hallaba al mismo tiempo que la falta de este Tratado hacía omitir en el del Excelentísimo Señor Pedro de Lucuze la delineación, y construcción de las obras, é impedia el aprenderlas en otros Autores" ${ }^{30}$. Por ello dedicó la sección primera de su libro a dar un

29 MARCH, J. M., obra citada en nota 15, pág. XIX.

30 Ibidem, págs. $\mathrm{XX}-\mathrm{XXI}$. 


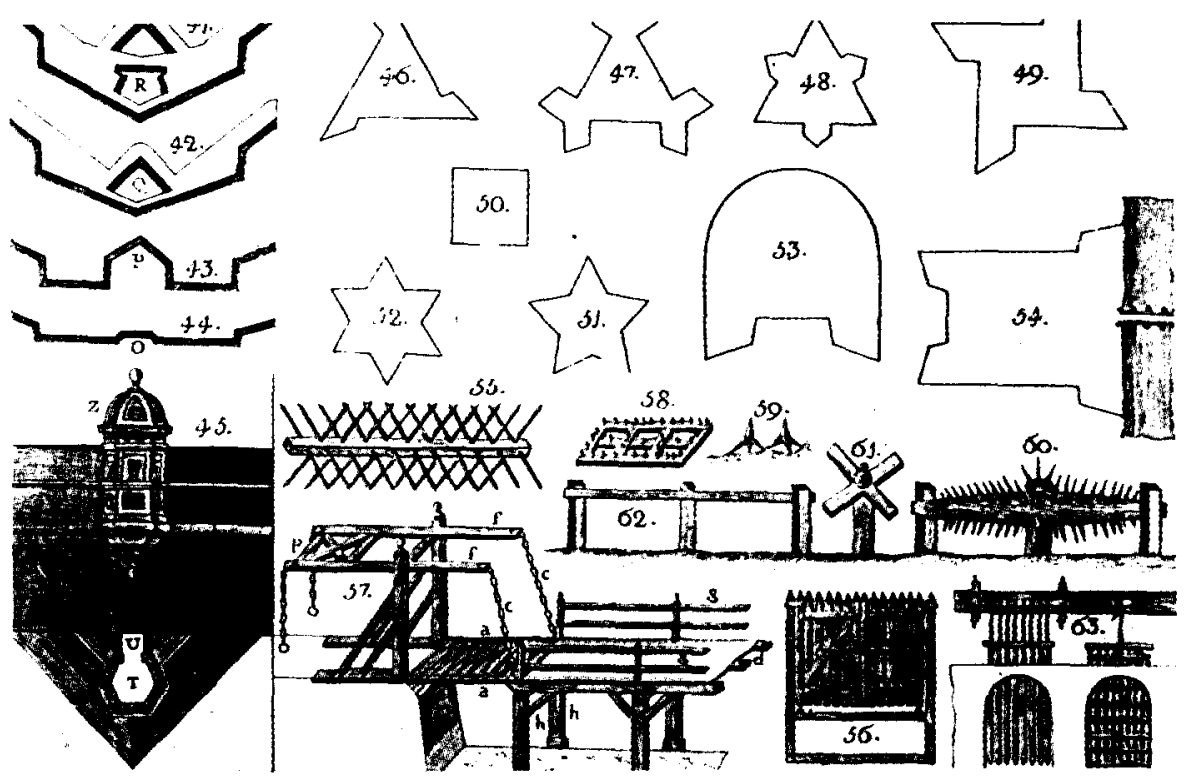

Lam 6. Lamina IV de los Principios de fortificación de Lucuce. Fig. 41: Plataforma en ángulo. Fig. 42: Pastel en ángulo entrante. Fig. 43: Baluarte plano. Fig. 44: Plataforma en muralla que corresponde al mar. Fig. 45: Elevación de una garita ( $\mathrm{Z}$ ), su plano exagonal ( $\mathrm{T}$ ) y el pasadizo o entrada en la garita. Fig. 46: Triángulo fortificado con tres medios baluartes. Fig. 47: Triangulo fortificado con dos medios baluartes sobre cada lado. Fig. 48: Triángulo con baluartes enteros en medio de los lados. Fig. 49: Cuadrado fortificado con medios baluartes en los ángulos. Fig. 50: Reducto simple de base cuadrada. Fig. 51: Estrella. Fig. 52: Estrella exagonal. Fig. 53. Herradura de caballo. Fig. 54: Hornabeque para cubrir la cabeza de un puente sobre el rio. Fig. 55: Caballo de frisa. Fig. 56: Rastrillo. Fig. 57: Puente levadizo. Fig. 58: Espinos o rejas. Fig. 59: Abrojos. Fig. 60: Puerco espin. Fig. 61: Molinillo. Fig. 62: Valla. Fig. 63: Órgano.

extracto de los principios de las Matemáticas más importantes para todo oficial, que a su vez consta de tres partes: Aritmética, Geometria y Geometría práctica, dedicando, asímismo, tres láminas grabadas en Barcelona en 1781 por Pauner, a la forma de trazar las más diversas figuras geométricas.

La necesidad que los tratados de fortificación tenian de las Matemáticas y de la Geometría creó mala conciencia a algunos autores y traductores al publicar estas obras sin una introducción o complemento dedicado específicamente a tales ciencias. Un ejemplo lo ofrece José 


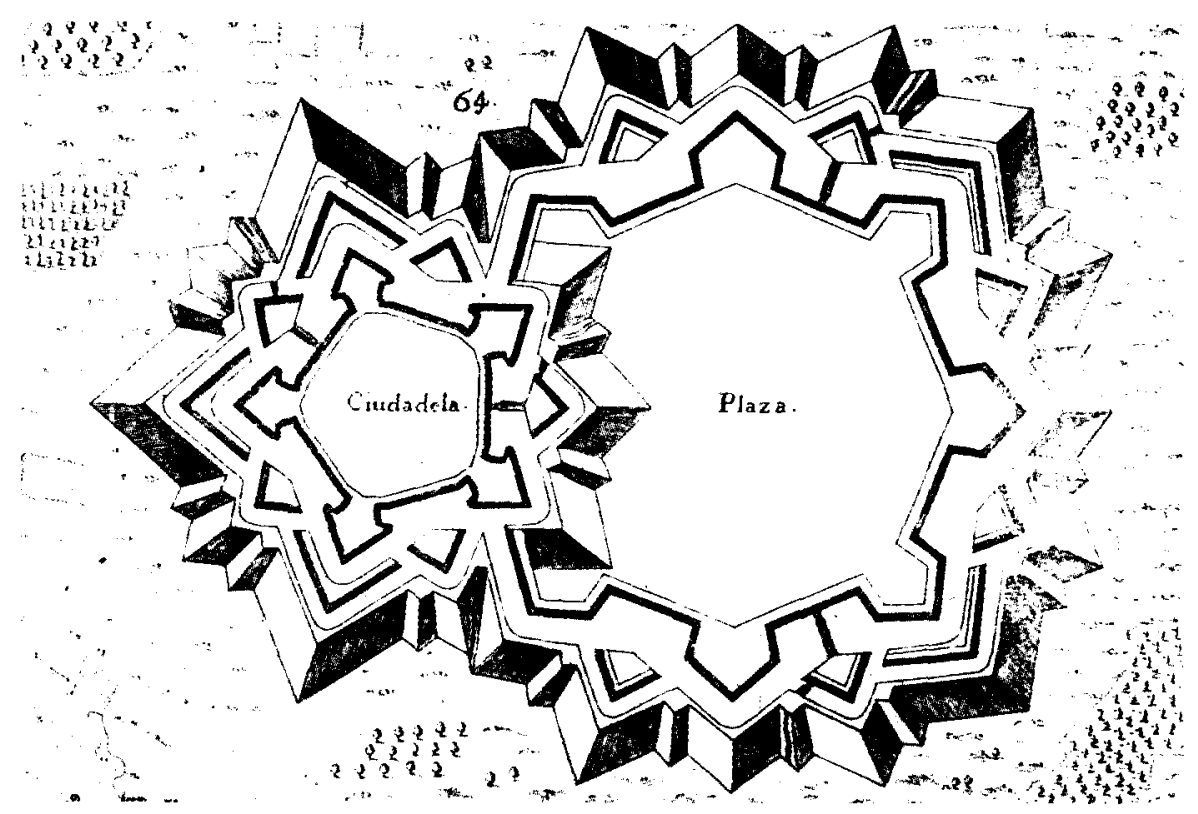

Lam 7. Lamina $V$ de los Principios de fortificación de Lucuce. Plaza fortificada con su ciudadela.

Caamaño y Gayoso, capitán y director de la Academia del Regimiento Inmemorial del Rey, quien vertió al español la Ciencia de Puestos Militares, o Tratado de las Fortificaciones de Campaña, aparecida en 1770 en Valencia ${ }^{31}$. En el prólogo del traductor se justifico la no inclusión de la Aritmética, Geometria y Fortificación, porque las Ordenanzas prometian otros tratados dedicados a estas disciplinas y debido a que no faltaban en el Regimiento buenos manuscritos, que les suplieran y que esperaba que saldrian publicados algún dia. Caamaño añadía lo siguiente: "Fuera de ésto, siempre deben Vms. estudiar la Fortificación de Campaña que aqui se les ofrece; y asegurarse todos, que fuera de la Arquitectura Militar, aunque estudiaran muchos Tratados de Matemáticas, no sacarian de ellos tanta instrucción para manejarse en Campaña, como les ofrece este pequeño Libro" ${ }^{32}$. El traductor no quiso omitir en la publicación las nociones básicas de Geometria del texto original por tres razones: por no

\footnotetext{
1 LE COINTE, J. L., obra citada en nota 5.

32 LE CONTE J. L., obra citada, fols. 6 reverso y 7 anverso.
} 


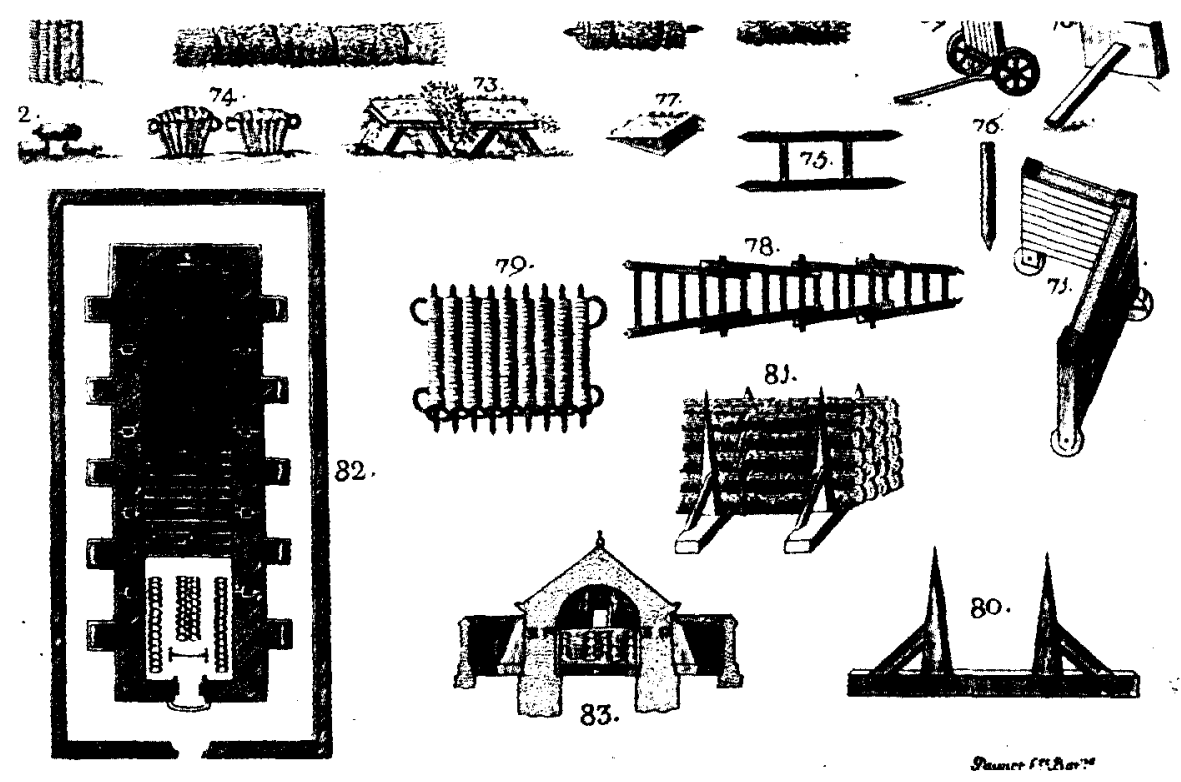

Lamina 8. Lamina VI de los Principios de fortificacion de Lucuce. Pertrechos que facilitan la construcción de las obras de campaña y plaza. Fig. 65: Cestón. Fig. 66: Fagina. Fig. 67: Salchichón. Fig. 68; Fagina o fajo de zapa. Fig. 69: Mantelete portátil. Fig. 70: Mantelete sencillo antiguo. Fig. 71: Mantelete doble antiguo. Fig. 72: Saquillos de tierra, que forman tronera. Fig. 73: Tepes, que forman troneras para fusiles. Fig. 74: Cestillos que forman tronera. Fig. 75: Blinda. Fig. 76: Pilote. Fig. 77: Tope de figura triangular. Fig. 78: Escalera compuesta de cuatro pequeñas. Fig. 79: Zarzo. Fig. 80: Candelero. Fig. 81: Parapeto para fagina.

defraudar la traducción, porque su contenido era suficiente para trazar los ejemplos que daba el autor, y para que sirviera a aquellas personas que quisieran formarse en ella sin estudiar el resto del libro. Así, el capitulo primero se dedica a los fundamentos que de esta disciplina debe saber todo oficial, analizándose el punto, la linea, el circulo, los ángulos, los triángulos, las superficies y los sólidos. La Geometría práctica tiene un papel importante en él, pues se describen los instrumentos necesarios para trazar figuras geométricas sobre el terreno, como la cadenilla, el grafómetro, piquetes, nivel, plomada... 


\section{FINALIDAD DE ESTOS TRATADOS}

La mayoria de estos libros sobre fortificación tenian por finalidad la enseñanza de los oficiales del ejército en general, sin que apenas salieran a la luz tratados específicos dedicados a los ingenieros militares. En este sentido tan sólo se puede citar aquí la obra de Muller de 1769, publicada para ser empleada en la Real Academia de Matemáticas de Barcelona. Su traductor, Miguel Sánchez Taramas, le pensaba - siguiendo al autor, quien de contínuo aludiria a este cuerpo- para formar a los ingenieros en cuanto fuera necesario en este ramo de la profesión. Tal texto debió ser una obra básica en las escuelas españolas durante todo el último tercio del siglo XVIIl. Hasta 1801 no se publicaria otro tratado especializado dirigido a este cuerpo con la aparición del Tratado de castramentación del ingeniero Vicente Ferraz, profesor de la Academia de ingenieros de Alcalá de Henares, aunque el tema afectaba, sobre todo, a la formación de los mandos militares ${ }^{33}$.

Sin embargo, predominan los textos escritos para que sirvieran, en general, en las diversas escuelas de oficiales del ejército, o a un determinado centro docente. Este es el caso, por ejemplo, de la Ciencia de puestos militares de Le Cointe, destinado por Joseph Caamaño y Gayoso, su traductor, a la enseñanza de la Academia del Regimiento Inmemorial del Rey ${ }^{34}$, y del suplemento de 1781 de March al texto de Lucuce, dedicado a los caballeros cadetes del Regimiento de Dragones de Sagunto ${ }^{35}$. Le Cointe habia escrito su obra con destino a los oficiales de inferior rango, ocupándose únicamente de aquellos puestos a donde po-

${ }^{33}$ Ferraz, Vicente. Tratado de castramentación ó Arte de campar, dipuesto para el uso de las Reales Escuelas Militares, del cargo del Real Cuerpo de Ingenieros, por.... Teniente Coronel é ingeniero ordinario del ejército. Madrid, en la Imprenta Real por D. Pedro Pereyra, impresor de Cámara de S. M. , año de 1800. 8 hojs. 489 págs., XX láms., 1 láms. $20 \mathrm{cms..}$ B. N. : $3 / 45,510$.

${ }^{34}$ LE COINTE, J. L. obra citada en nota 5 , fol. 3 anverso y reverso. "Este tratado, -dice Joseph Caamaño y Gayoso- aunque breve. es útil para los Oficiales del Exército". Indicaba que salía a la luz "principalmente para la Juventud del Inmemorial del Rey" a cuyo cargo estaba el Conde de Aranda.

${ }_{35}$ MARCH, J. I., obra citada en nota 15. March expresó la finalidad de este libro en la portada, despues del titulo. Lo dedico a D. Eugenio Bretón, Teniente General de los Reales Ejércitos, Consejero nato en el Supremo de la Guerra e Inspector del Cuerpo de Dragones, quien en la carta publicada en la obra indico, que además de ser útil este libro para la instrucción de los cadetes de su Regimiento, lo era "para los demás del Cuerpo de Dragones y aún de todo el Exército". Sanchez Taramas, entonces Director de la Real Academia Militar de Matemáticas establecida en Barcelona. también dio su aprobación a este texto en su carta fechada en esa ciudad el 27 de noviembre de 1780 . 


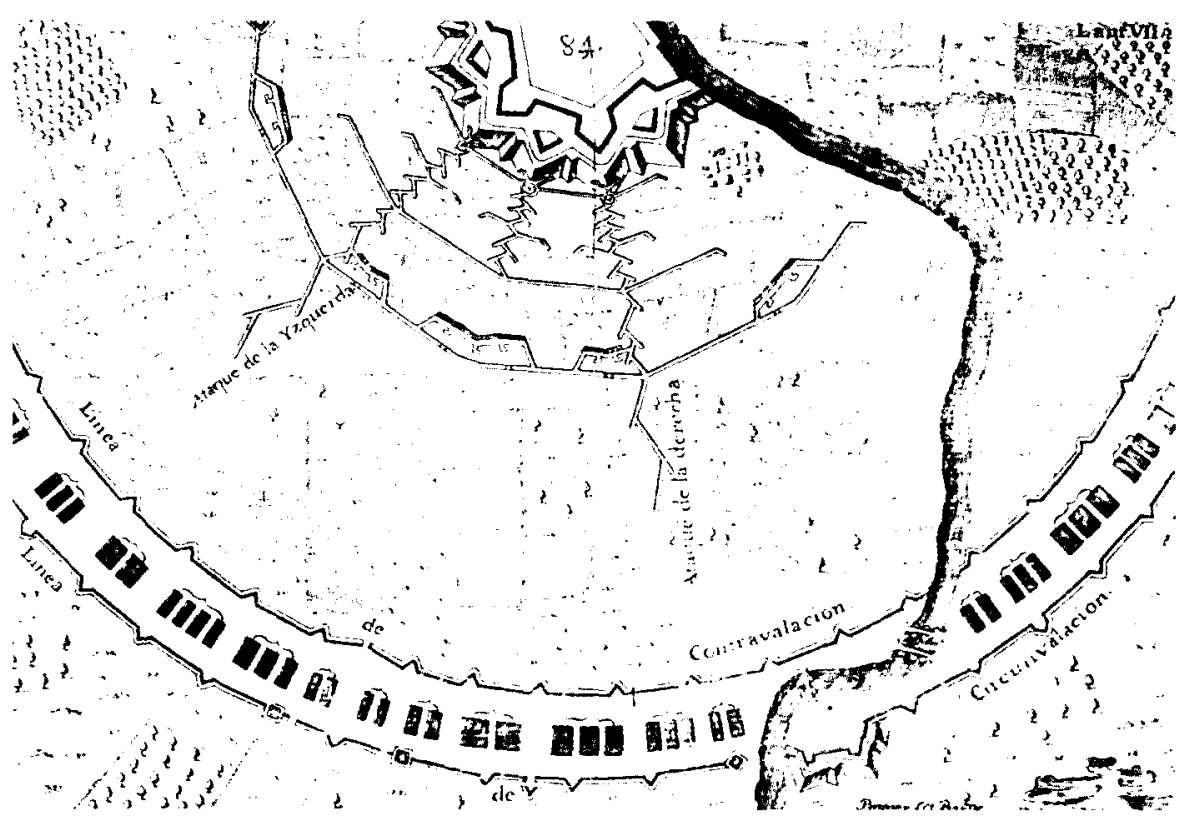

Lamina 9. Lamina VII de los Principios de fortificacion de Lucuce. Ataque a una plaza fortificada.

dian ir destacados con 30,50 o 100 hombres ${ }^{36}$. Este libro trataba, por consiguiente, de la forma de atrincherarse en esos puestos y de hacer reductos; prescindió de la fortificación especifica.

El tratado de Lucuce tenia la intención de proporcionar los rudimentos de la fortificación a los jóvenes oficiales y cadetes que comenzaban a servir en el ejército. Para lograrlo proporcionaba definiciones breves, claras e inteligibles de los principales términos pertenecientes a las distintas partes de una plaza fortificada, de las obras de campaña y de su aplicación al sitio y defensa de las fortalezas. Este hecho le hizo prescindir de las citas, aunque los conceptos los entresacó tanto de los autores

3á Le Colnte, J. L., obra citada, págs. 7-8. El libro se dedica sobre todo a la forma de atrincherarse en los puestos. Se introduce con un capitulo sobre la Geometria práctica, que debe saber un oficial. El autor de la obra pensó escribirla al ver durante la dirección de realización de destacamentos en la guerra del Piamonte, Italia, lo desorientados que se hallaban los jovenes oficiales, "que no tienen idea alguna de lo que es Fortificación quando le mandan atrincherarse". 
españoles como de los extranjeros, que habian tratado con profundidad esta materia.

Lucuce distinguió en su libro dos grados distintos de conocimientos en esta ciencia según se tratara de formar o a los Cuerpos facultativos de ingenieros y de artilleros, o a los oficiales de Infanteria, Caballeria y Dragones. Aquellos debian estudiar esta disciplina en profundidad para poder diseñar los proyectos y ejecutar las obras. En su opinión les bastaba a éstos últimos con conocer las nociones más generales en todo lo referente al ataque y a la defensa de las plazas fortificadas. También opinaba que los ingenieros y artilleros eran bien preparados en Matemáticas por sus Academias Militares y según exigian las Ordenanzas del 22 de julio de 1739 y del 29 de diciembre de 1751. Asi, su libro se dirigia a todos aquellos oficiales jóvenes y cadetes, que no habian podido cursar estos estudios en sus academias o por hacer falta en sus Cuerpos o por no poder subsistir fuera de ellos, careciendo de toda instrucción.

Los tres libros de Le-Blond - los dedicados a los elementos de fortificación, al ataque y a la defensa de las plazas - se publicaron, entre
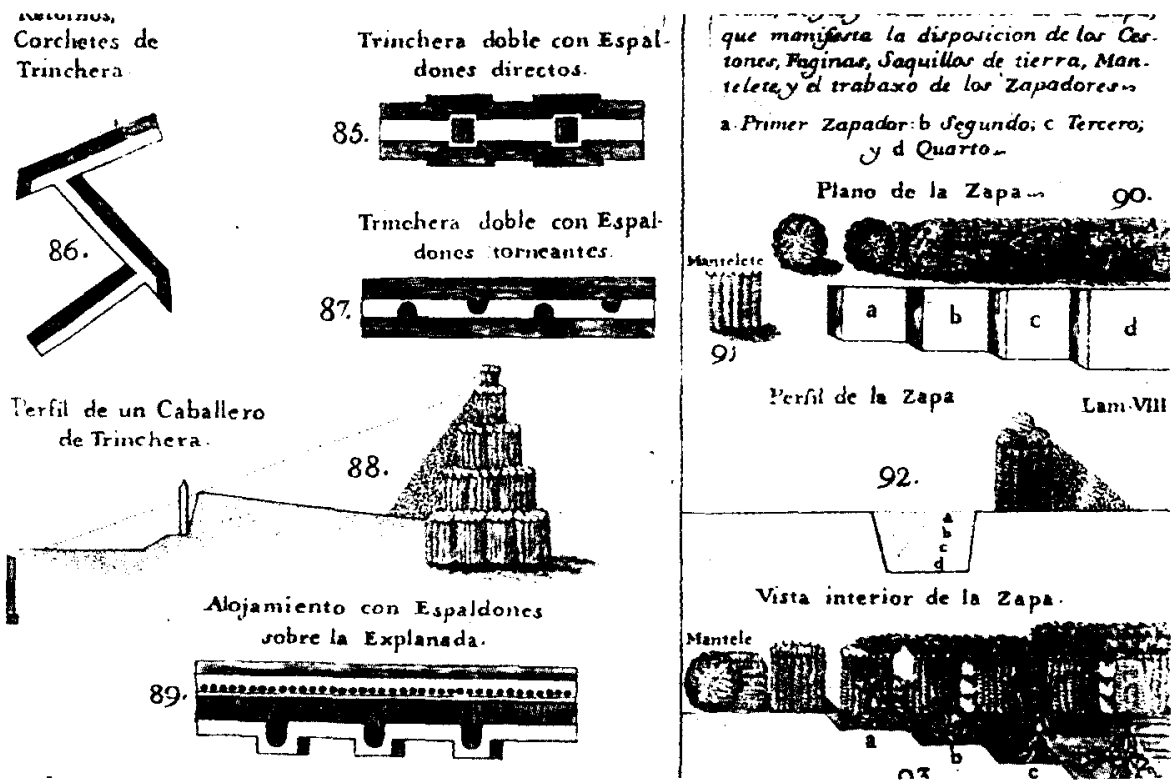

Lamina 10. Lamina VIII de los Principios de fortificacion de Lucuce. Retornos y corchetes de trincheras. Plano, perfil y vista interior de la zarpa. 


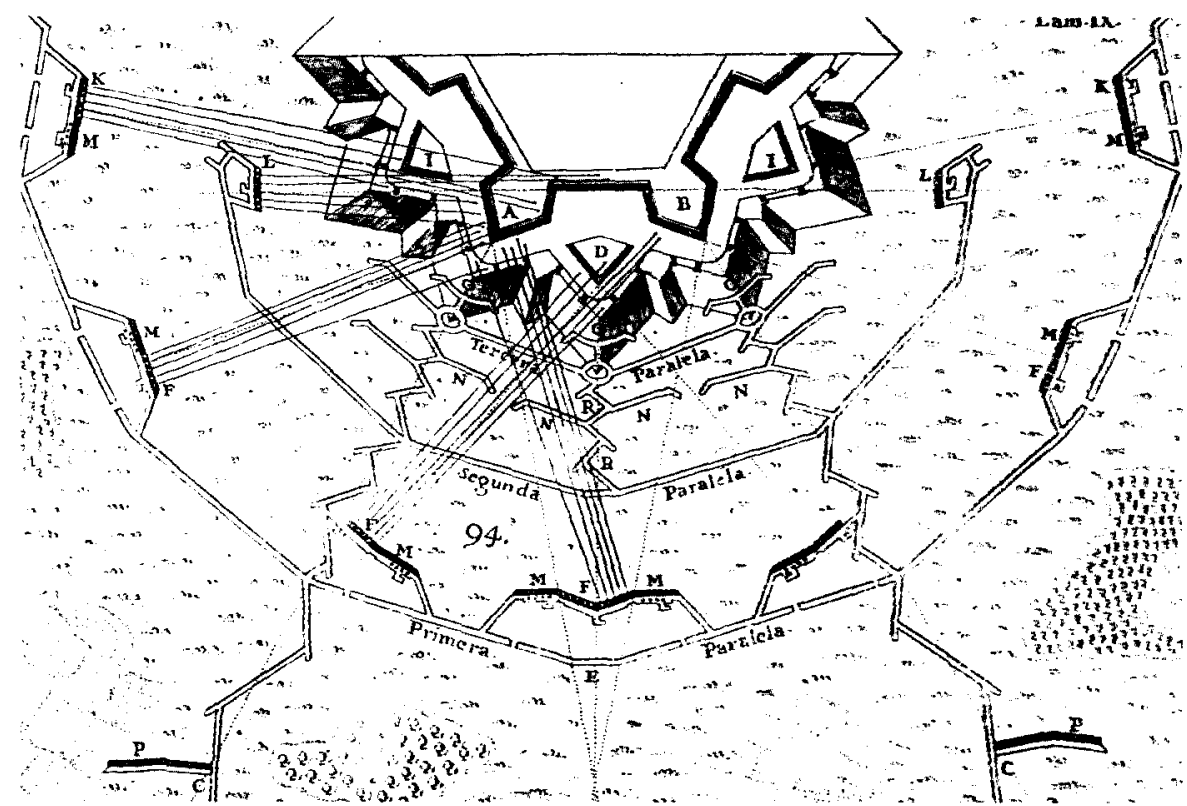

Lámina 11. Lamina IX de los Principios de fortificacion de Lucuce. Lineas del ataque hasta la formación de los caballeros sobre la explanada.

1776 y 1777 vertidos al español por un anónimo traductor, obedeciendo los deseos del Conde de O'Reilly, Inspector General de Infanteria, quien se habia preocupado especialmente por el fomento del arte de la guerra. En el prólogo del autor a los Elementos... el maestro de Matemáticas del Delfín de Francia señalaba que "una de las partes más esenciales del Arte Militar es la fortificación, cuyo conocimiento no sólo interesa a los Ingenieros y Artilleros, sino también a los Oficiales generales que pueden tener a su cargo el ataque y la defensa de las Plazas" " ${ }^{37}$. El traductor dirigía este libro a la instrucción de los militares en general, considerándole como el mejor de los tratados escritos sobre el tema debido a su método, precisión y claridad. Las seis ediciones publicadas en Francia hasta entonces eran según su opinión una prueba inequivoca de la bon-

LE BLOND. G.. Elementos de fortificacion... obra citada, en nota 9, pag. XXI, prologo del autor. Le Blond señalo como objetivo principal de este tratado: «dar ideas exactas sobre la fortificacion, y manifestar sus reglas y principios fundamentales para que aualquiera por si solo pueda aplicarlos últimamente a la construcción de todas las especies de obras" (págs. XXII-XXII) 
dad del tratado, a la que también había que añadir los juicios favorables de varios autores especialistas, que le calificaban como una de las principales obras de su especie ${ }^{38}$.

El traductor indicó en su prólogo que los Elementos de fortificación de Le-Blond se habian ya publicado en España en una obra titulada Ciencia de Militares, impresa en Cádiz en 1757, vertida al español por Manuel Centurión Guerrero de Torres, Teniente del Regimiento Real. Sin embargo, añadia que en su edición de 1776 - que se reimprimiría ya en 1805- el texto estaba aumentado en una tercera parte con unas observaciones muy útiles, el compendio de fortificación antigua y los sistemas mejor fundados de la moderna ${ }^{39}$.

Charles Sevin de Quincy se propuso con su Arte de la guerra dar unas instrucciones de carácter general a los militares basándose históricamente en la relación exacta de todas las acciones bélicas ocurridas en Europa durante el reinado de Luis XIV: “Es preciso confesar, que la Historia de muchos siglos a esta parte no nos refiere tan crecido número de batallas, tanto por mar, como por tierra; tan memorables ataques, tantos, y tan bellas defensas de Plazas, y en fin, tan excesivo número de acciones particulares, como se ha visto después del nacimiento de este grande Príncipe hasta su muerte ${ }^{40}$.

\section{AUTORES, TRADUCTORES Y PROMOTORES}

La mayoría de los autores y traductores españoles de estos libros fueron oficiales del ejército, que desempeñaban diversos cargos y funciones. Muy pocos pertenecieron al cuerpo de ingenieros militares. Miguel Sánchez Taramas y Pedro de Lucuce destacan de entre los españoles. El Marqués de Quincy era teniente general de Artillería. Muller ejercia como profesor de Artilleria y Fortificación en la Academia de Woolwich, conjugándose en sus obras, impresas en el tercer cuarto del siglo, los

\footnotetext{
Ibidem, pag. VI

39 lbidem. págs. $X-X \mid$.

40 SEVIN DE QuinCY, CH., obra citada, en nota 6, págs. 1-2.
} 
tratados de matemáticas con los de artillería y fortificación ${ }^{41}$. Le Cointe publicó su libro habiendo sido teniente de Infantería, capitán de Caballeria y de la Academia Real de Nimes... Le-Blond era maestro de Matemáticas del Delfín y de los Condes de Provenza y de Artois. Su anónimo traductor llegó a afirmar de él en el prólogo que no restaba interés a su obra la circunstancia de no ser ingeniero ${ }^{42}$. José Ignacio March firmó su libro como capitán del Regimiento de los Caballeros Cadetes de Dragones de Sagunto. Raymundo Ortiz de Zárate, traductor del libro del Marqués de Quincy, era subteniente del Regimiento de Cantabria. José Caamaño y Gayoso, que lo fue del tratado de Le Cointe, tenía el grado de Capitán del Regimiento Inmemorial del Rey y dirigia la Academia de este Regimiento por nombramiento del Coronel Conde de Fernán Núñez.... Asi, pocos de los autores de estos tratados eran ingenieros militares reconocidos, cuerpo preferido para desempeñar la docencia en los centros de formación del ejército.

El asturiano Pedro de Lucuce desempeñaba los cargos de Director de la Real Academia Militar establecida en Barcelona y de Mariscal de Campo de los Reales Ejércitos en 1772, año de la aparición de sus Principios de fortificación. Era profesor en ella desde 1736, habiéndosele encomendado al año siguiente la redacción del proyecto de reglamento de las Academias. Cuando Calabro fue cesado, se le nombró su director propietario el 22 de mayo de 1739, cargo que desempeñó hasta 1774, que fue asignado director del Ramo de Academias, falleciendo en esta función en 1779. Al crearse el 23 de octubre de 1756 la Real Sociedad

"En la biblioteca del Instituto y Observatorio de Marina de San Fernando (Cádiz) (Catálogo publicado en San Fernando, Cadiz, Observatorio de la Marina, diciembre de 1974) se conservan varias obras de Muller: A treatise containing the elementary part of fortification regular and irregular. 2. ${ }^{2}$ ed.. London, 1756 (Catálogo, núm. 582). También: A treatise containing the practical part of fortification. (Cat. 646). Asimismo: Muller, J., Elements of mathematics. 3. ${ }^{a}$ ed.. London, 1756 (Cat. 651). A treatise of artillery. 2. ${ }^{a}$ ed.. Paris, 1768. (cat. 672). La 3. ${ }^{a}$ ed publicada en London. 1780. (Cat. 1068). Appendix of Supplement to the treatise of artillery, London, 1768. The attac and defence of tortified places. 3 ." ed.. London, 1770. (Cat. 699). Asi en la obra de Muller se conjugan los tratados de matemáticas con los de artilleria y fortificación. Véase nota 11

${ }_{42}$ LE BLOND. G.. Elementos de fortificacion, obra citada, pág. $V$. El traductor dice lo siguiente: "En efecto, ningun escrito de fortíficación ha salido a luz, que pueda compararse con el metodo. precision y claridad de estos Elementos: las seis ediciones que se han publicado forman una prueba nada equivoca de su mérito. el qual ha sido igualmente reconocido por diferentes Autores de fortificación, que recomiendan la obra del Señor LeBlond. como una de las más perfectas en su especie, utilisima a los Militares. y digna de los talentos de este sabio Escritor; sin que la circunstancia de no haber sido Ingeniero. pueda disminuir el debido aprecio a la crítica y discernimiento con que trata una materia puramente elemental». 
Militar de Matemáticas de Madrid, se le nombraría su director, ocupación en la que estuvo hasta 1760 , dedicándose a coordinar la realización de los libros de texto según los deseos del Conde de Aranda; pero este proyecto fracasaria debido a la dimisión de este último y a los conflictos surgidos entre Lucuce y La Croix. Fue, asimismo, responsable de la redacción de un curso de Matemáticas inédito, del cual se conservan algunos manuscritos de los apuntes tomados por los alumnos, en el que se incluyen ocho tratados; de ellos el cuarto se dedica a la fortificación y el octavo a la arquitectura civil ${ }^{43}$.

Miguel Sánchez Taramas era al publicarse en 1769 su traducción del libro de Muller capitán de infanteria, ingeniero ordinario y profesor de la Real Academia Militar de Matemáticas de Barcelona, función docente que desempeñaba desde 1774. Alcanzaría los rangos de teniente general de ese cuerpo, ingeniero en segundo y director de ese establecimiento entre 1784 y 1789, cargo en el que sucedió a Juan Caballero, siendo sustituido por Félix de Arriete ${ }^{44}$.

Todas estas obras fueron promovidas por destacadas personalidades militares españolas, a las que iban dedicadas. Ya antes se hizo referencia al Conde de O'Reilly, Inspector General de Infanteria, a cuya iniciativa se deben las traducciones de los tratados de Le-Blond. La versión del libro de Muller fue ofrecida por Sánchez Taramas a Juan Gregorio Muniain, Secretario de Estado y del Despacho Universal de Guerra y Teniente General, al que elogiaba por su especial inclinación por todo lo concerniente a la facultad de ingeniero. También la dedicó a Juan Martín Cermeño, teniente general de los Reales Ejércitos e Ingeniero General desde 1769. Por su parte José Caamaño y Gayoso dirigió la traducción del texto de Le Cointe al Conde de Aranda, que entonces era Capitán General de los Reales Ejércitos y Presidente del Consejo, quien desde su cargo de director general de artillería e ingenieros habia intentado promover la redacción de textos españoles para las academias militares españolas, dotando a la Sociedad Militar de Matemáticas de una buena

4: Sobre Pedro de Lucuce: Capel. H., Sanchez. J. E. y Moncada O. : De Palas a Minerva. obra citada, especialmente el capitulo $V$ titulado "la dirección de Lucuce y la reforma de 1739 ". págs. 126-146. Asimismo en este libro: "El curso manuscrito de Lucuce". págs. 224-231. Tambien en Capel, H. et alii: Los ingenieros militares en Espana. Siglo xvili. Repertorio biográfico e inventario de su labor cientifica y espacial. Barcelona. Universidad. Catedra de Geografia Humana. 1983. El curso manuscrito de Lucuce se titula: Curso Matematico para la instruccion de los Militares y se conserva en la Biblioteca Central de Ingenieros.

t4 CAPEL H. et alii. De Palas a Minerva, ibidem pags. 89, 113, 138, 139, 150, 189 , $190 \mathrm{n}, 198,235,236 \mathrm{n}, 250,251 \mathrm{n}, 295$ y 307. 
biblioteca ${ }^{45}$. Las Nociones militares de March, que contaron con la aprobación del propio Sánchez Taramas, iban dirigidas a Eugenio Bretón, teniente general de los Reales Ejercitos, Consejero nato en el Supremo de la Guerra e Inspector General del Cuerpo de Dragones.

\section{APROXIMACIÓN BIBLIOMÉTRICA: CITAS BIBLIOGRÁFICAS E INFLUENCIAS}

La mayoría de estos tratados se halla bajo las influencias de los sistemas de fortificación de Vauban y de los libros de Belidor, quien es, sin duda, el autor más citado. Muller y Le Blond aluden de continuo a la Ciencia de Ingenieros ${ }^{46}$ y a la Arquitectura hidráulica de este último ${ }^{47}$. El inglés puso en entredicho a Belidor por dar a los pilares de los puentes un espesor menor del justo, siguiendo sus teorias sobre la construcción de los muros, el método para cubrir las bóvedas, la realización de casamatas, y de las puertas, fachadas y plazas de las fortalezas... Muller se vanaglorió de haberle superado al proporcionar una tabla con la indicación del grueso de los pilares desde 6 a 24 pies de altura para arcos, cuyos anchuras están comprendidas entre los 20 y los 100 pies ${ }^{48}$. Le Blond incluyó en su Tratado de la defensa de las plazas un discurso de Belidor sobre el modo de volar hacia el foso las baterias, que establece el sitiador en el camino cubierto, que este autor no pudo incluir en el tratado de minas, que estaba redactando, al sobrevenirle la muerte.

Los sistemas de fortificación de Vauban fueron difundidos ampliamente por Le-Blond en los Elementos de fortificación, quien en el Tratado de defensa de las plazas incluyó sus tablas para mejor abastecerlas ${ }^{49}$. En el Tratado del ataque de las plazas siguió sus métodos y máximas, refiriéndose a que a él se debia la invención de las paralelas y baterias a rebote, que habian acortado la duración de los sitios, haciéndoles más seguros y menos ingratos. Muller aludió a Vauban al tratar tanto de la elevación del parapeto de una plaza fortificada como del empleo de la

45 Capel. H., ibidem. págs. 178-179.

${ }^{4}$ BELIDOR, B. F., La Science des ingenieurs dans la conduite des travaux de fortification et d'Architecture Civile. Paris. 1729. B. N.: 2/21,653.

4 Belidor. B. F., Architecture Hydraulique. Paris, 1737-53. 2 tomos en 4 vols. B. N.: 2 $51,458-60$ y $3 / 17.800-3$

is MULLER, J.. obra citada. en nota 11. prólogo del autor. págs. 11

49 LE BLond, G.. Tratado de defensa de las plazas, obra citada. en nota 8. 


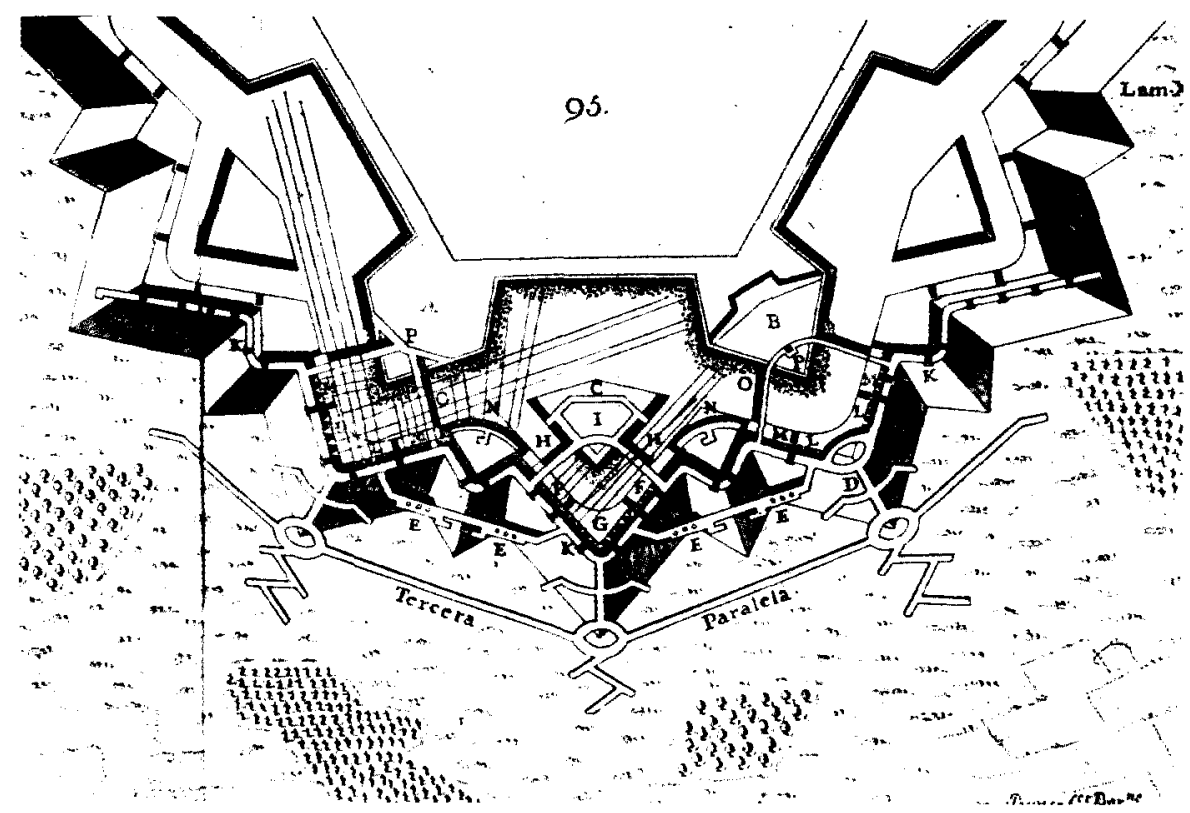

Lamina 12. Lámina $X$ de los Principios de fortificacion de Lucuce. Representación de todas las obras desde la tercera paralela hasta las brechas de la plaza. A y B. Baluartes del frente atacado. C. Rebellin del propio frente. D. Caballero de trincheras. E. Baterias de pedreros. F. Baterías en brecha contra el rebellín. G. Baterías contra las defensas del rebellin. H. Pasos del foso de rebelín. I. Alojamiento sobre el rebellín. K. Alojamiento sobre la explanada del frente. $L$. Baterias contra las defensas de los baluartes. M. Baterias en brecha contra dichos baluartes. N. Baterias contra la cortina. O. Pasos del foso de los baluartes. P. Alojamientos sobre los baluartes.

bóveda gótica en los almacenes de pólvora y de sus dimensiones ${ }^{50}$. Sevin de Quincy también se refirió a él y publicó en la tercera parte del Arte de la guerra el tratado de minas compuesto por este jefe de los ingenieros franceses ${ }^{51}$.

Muller citó, asimismo, libros como Le perfait ingenieur français ou le fortification offensive et défènsive de Deidier ${ }^{52}$ y el Traité des Ponts de

50 MULleR, J.. obra citada en nota 11.

1 SEVIN DE QUINCY, Ch., obra citada, tercera parte, capítulos XVII al XXVI.

52 DElOIER, Le perfait ingenieur français au la fortification offensive sive defènsive. Nouvelle edition. Paris, 1757. B. N.: 2/16.967. 


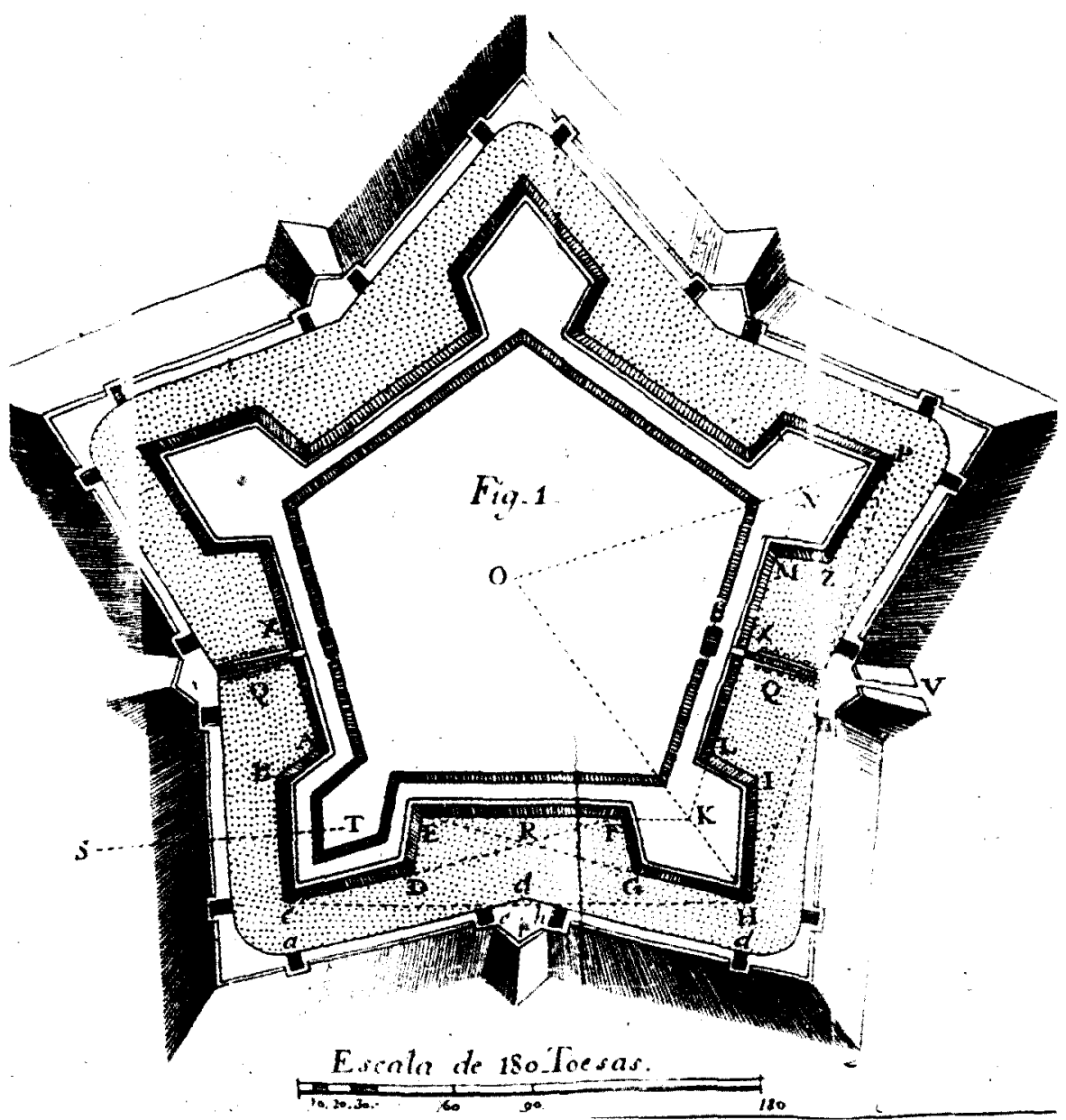

Lamina 13. Lamina 1 de los Elementos de fortificacion de Le Blond. Segunda edición española de 1805, publicada en Madrid por Gómez Fuentenebro. Plano de una plaza fortificada, en el que se indican los baluartes, ángulos de la tenaza $(\mathrm{CRH})$, contraescarpa, plaza de armas (cih)... Grabado de Manuel Rodriguez.

Gautier $^{53}$. Se refirió en su tratado a Parent, miembro de la Academia de Ciencias de París, y a su teoría sobre la resistencia de algunos materiales como la de los tablones del pino y de la encina, tesis de la que discrepaba, fundándose para ello en una serie de experimentos realiza-

${ }^{5.3}$ Gautier, Traité des Ponts. Paris, 1728. 


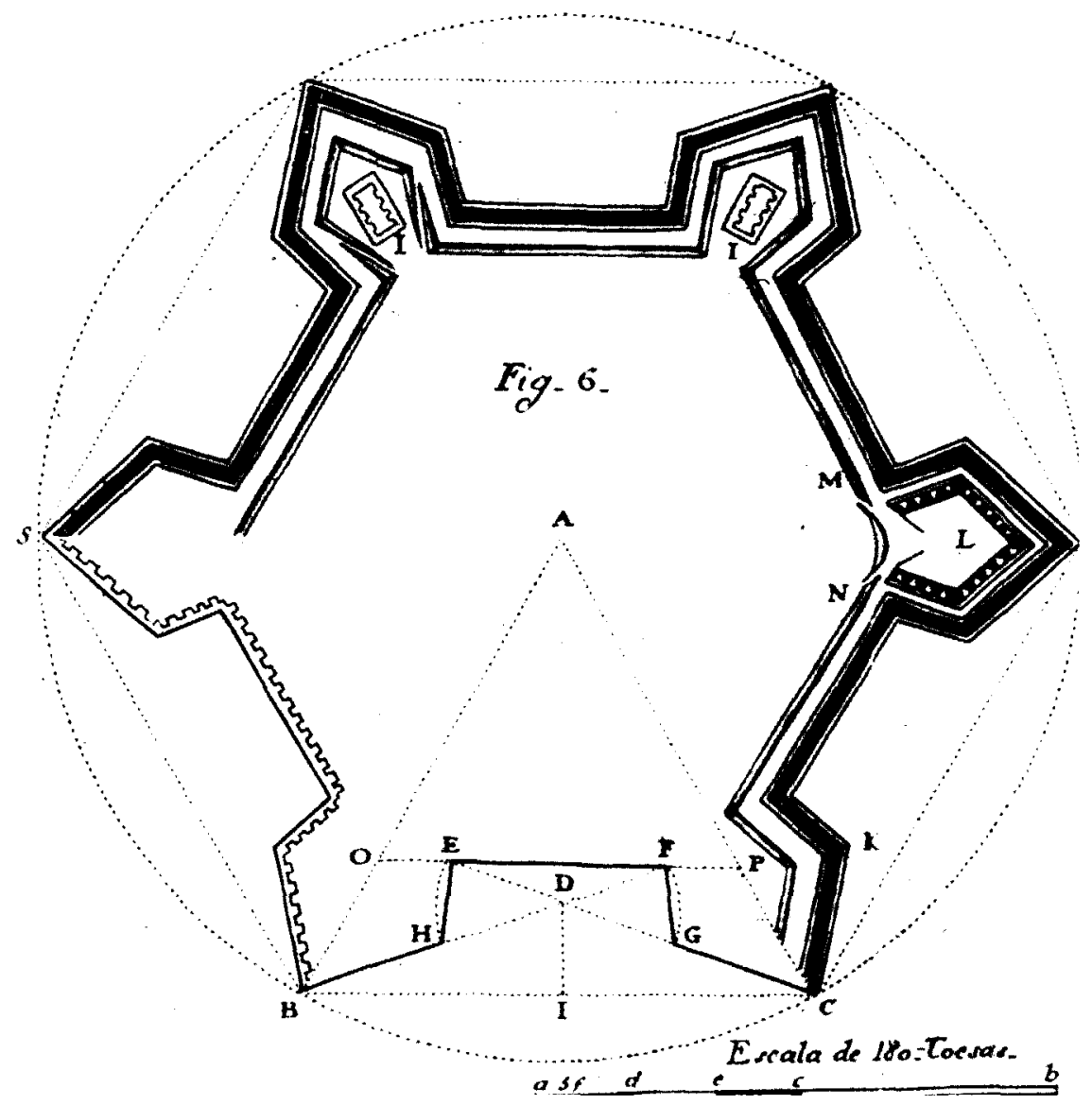

Lamina 14. Lamina 3 de los Elementos de fortificacion de Le Blond. Plano para delinear la línea magistral del recinto de una plaza. Sistema del Mariscal Vauban.

dos por él. Le Cointe se basó en todo lo referente al ataque y a la defensa de los puestos militares en L'Ingenieur de campagne ou traité de la fortification passagère de Clairac ${ }^{54}$ y en el Tratado del Ataque de las Plazas de los antiguos de Folard, publicaciones que consideró unos precedentes de su libro, indicándo en él, que los autores, que escribieron

14 La Mamie de Clalrac, Louis Andree de, Lingenieur de campagne ou traite de la fortification passagere. Paris, 1749. B. N.: 3/35,794. Tambien en la BIOMSF. cat. 525. 


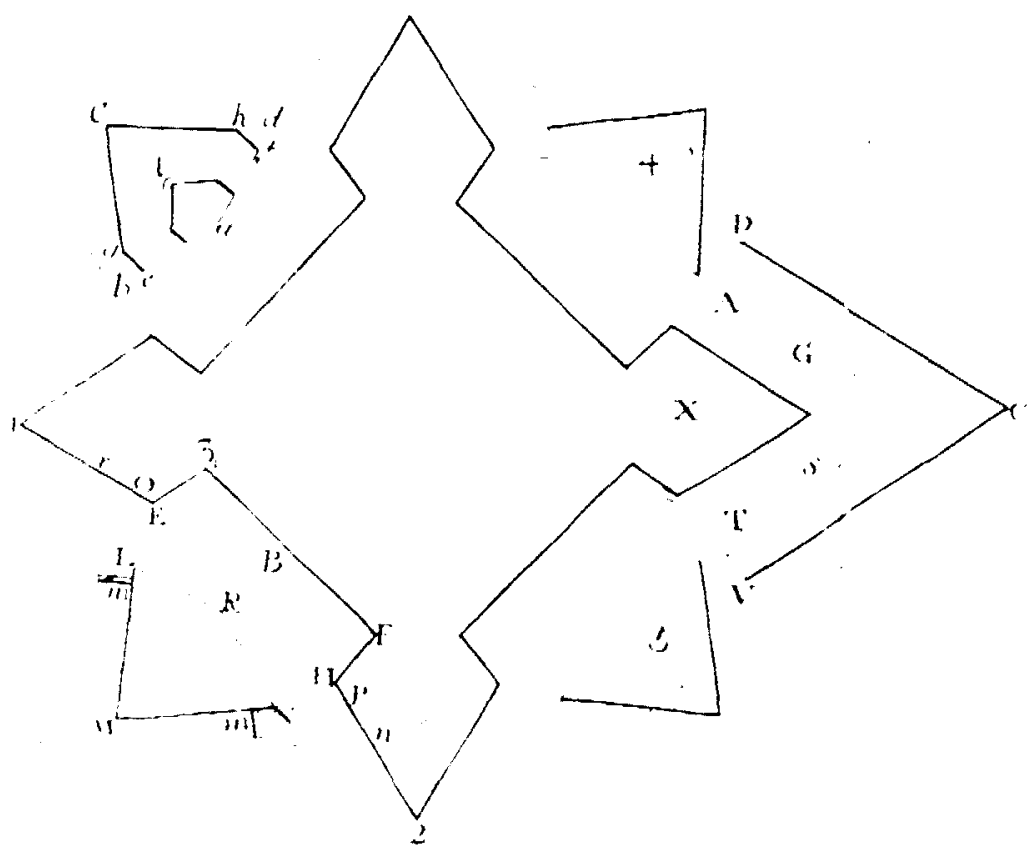

Lámina 15. Lámina 8 de los Elementos de fortificación de Le Blond. Delinear el rebellin u obra de figura triangular que se construye delante de las cortinas. Delinear la contraguardia u obra que cubre las caras del baluarte. 
después, se habian reducido a copiarlos y a estructurarlos ${ }^{55}$. Estas mismas obras de Clairac - de quien tomó sus ideas sobre la forma de fortificar la iglesias, publicando casi literalmente su texto $-y$ de Folard aparecen citadas en el Tratado de defensa de las plazas y en el Tratado de ataque de las plazas de Le Blond. Tal autor también se basó, sobre todo, en las Reflexiones militares del Marqués de Santa Cruz ${ }^{56}$ en lo referente a las capitulaciones de las plazas, en los Eléments de l'Art Militaire de Nicolás D'Hericourt ${ }^{57}$ y en las Obligaciones de los gobernadores de las plazas de De Ville.

Le Blond empleó, por tanto, una bibliografía numerosa, que constaba especialmente de libros franceses, para la redacción de sus obras. Así, en sus Elementos de fortificación citó libros tan interesantes y representativos como Les travaux des mars de Alain Manesson Mallet ${ }^{58}$, el Traité de Fortification de Jacques Ozanam ${ }^{59}$ y el ya indicado Le perfait ingenieur français de Deidier ${ }^{60}$, e hizo uso también del artículo dedicado a la fortificación de la Enciclopedia. Otros muchos textos aparecen reseñados

${ }^{55}$ FolaRd, Tratado del Ataque de las Plazas de los antiguos. Le Blond también le citó en su Tratado de la defensa de las plazas, al referirse al abastecimiento de viveres de las plazas fuertes entre los antiguos y en lo referente a las obligaciones del gobernador. March se refirió asímismo a Folard criticándole por su falta de consideración por la caballería, ya que destacaba en su Comentario de Polibio, Liv. III, cap. XIII, la superioridad de la infanteria.

s6 Santa Cruz de Marcenado, Marqués de Alvaro Navia Ossorio, Reflexiones militares. Madrid, Comisión Española de Historia Militar, 1984. B. N.: 4/223,664.-Turín, por Juan Francisco Mairesse, 1724-26.

57 Hericourt, Nicolás d', Eléments de l'Art Militaire. La Haye, 1739. B.N.: 2/117. Otras ediciones en: París. 1748: 5/5,201 y 3/47, 667-8, y Paris, 1752: 2/39,632-4.

${ }^{58}$ Mallet, A. M., Les travaux des mars, ou l'art de la guerre. París, (s.a.). B. N.: 5/7, 403.-Les travaux des mars, ou la fortification nouvelle. París, 1671-72. 3 vols. B. N.: 3/31, 255-7. Otra edición: Paris, 1684. 3 vols.: B. N.: 2/18,116-8 y 3/49, 704-6.-París, 1691: B N.: 2/19, 038-39.-París, 1791: B. N.: 2/70, 512-14.-En la Biblioteca del Observatorio de la Marina de San Fernando (Cádiz) se guarda de Mallet: Description de l'Univers, contenant les différens systémes du monde, les cartes générales et particuliéres de la Géographie ancienne et moderne, les plans et les profils des principales villes et des autres lieux plus considerables de la terre. Paris, 1683. 5 vols. Cat. 191.

59 Ozanam, J., Traité de Fortification... Paris, 1694. B. N.: 3/46, 567. Otros libros suyos: Cours de Mathematique. Paris, 1693: B. N.: 6-i: 349. Otra ed.: Paris, 1699: B. N.: 2/18, 387-91. Tambièn: París, 1720, en 5 vols.: BIOMSF: Cat.: 310.-Dictionaire mathématique, ou idée génèrale des mathématiques. Amsterdam, 1691: B. N.: 3/50, 601. En la BIOMSF se conserva otra edición aparecida en este mismo año, pero en París: Cat. 217. - La Géometrie practique. Paris, 1684: B. N.: 3/4,735. Otra ed:: 1762: B. N.: 3/24,171.-Récréations mathematiques et physiques. Paris, 1770. 4 vols. BIOMSF: Cat.: 693.-Méthode de lever les plans et les cartes de terre et de mer: ouvregre augmentée par $M$. Audierne. Paris, 1781. BIOMSF: Cat. 827.

${ }^{60}$ DEIDIER, obra citada, en nota 52 


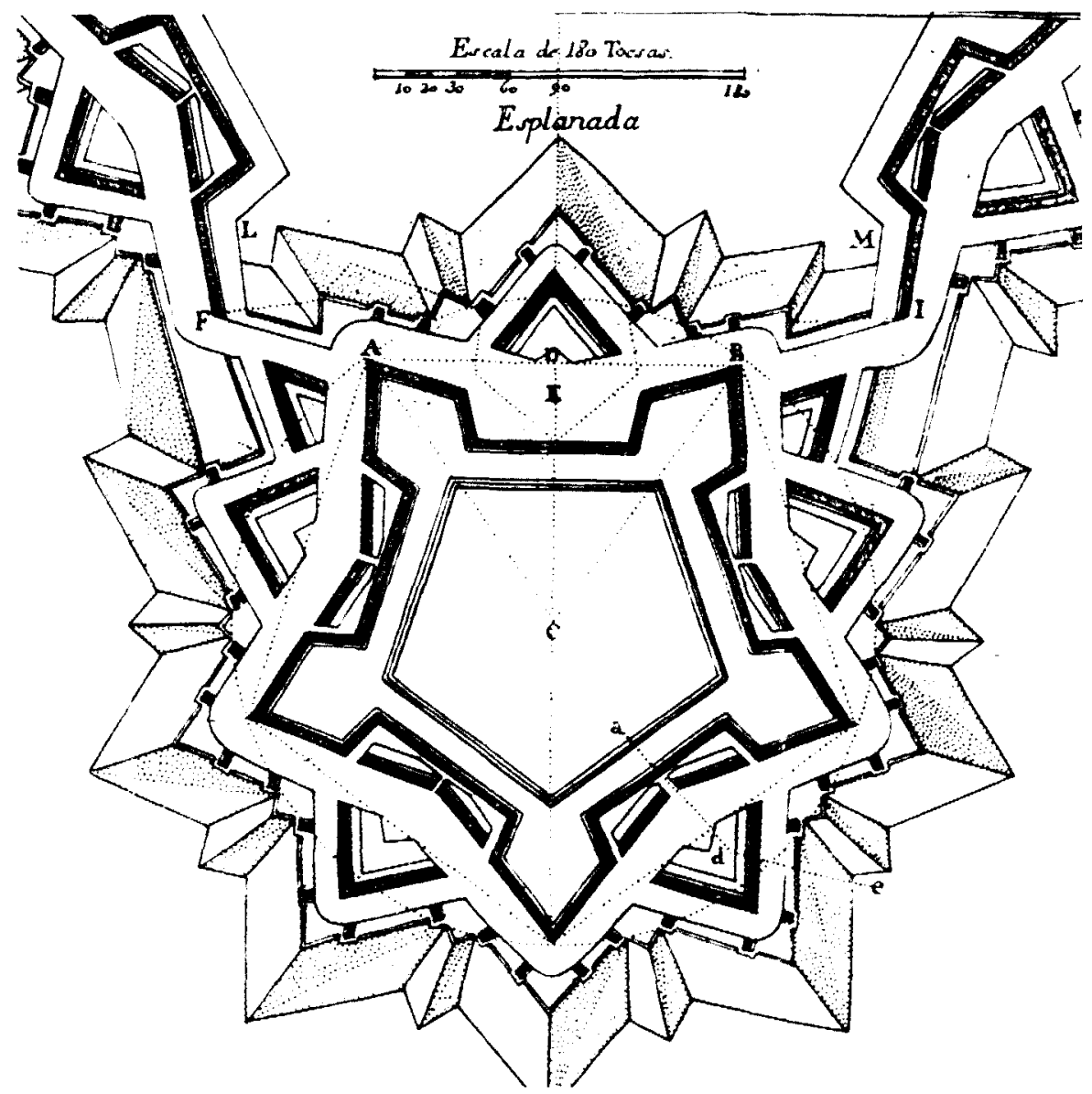

Lamina 16. Lámina 12 de los Elementos de fortificación de Le Blond. Ciudadela o pequeña fortaleza situada en el recinto de una plaza, parte dentro de ella, parte hacia la carnpaña. Forma de construir las ciudadelas.

en ese tratado, como una serie de publicaciones de los Marqueses de Feuquières y Maffei, de Daniel Speckle, de Folard...

Los sistemas franceses de fortificación, aparecidos durante el período barroco, difundidos en la España ilustrada por Le Blond, se hallan de alguna forma presentes en estos tratados, perviviendo a lo largo del primer tercio del siglo XIX en obras tales como, por ejemplo, el Tratado completo del arte militar de José Mariano Vallejo, aparecido ya en 
$1812^{61}$. Son, asi pues, deudores de Errard de Bar-le-Duc ${ }^{62}$, del caballero De Ville ${ }^{63}$, del Conde de Pagan ${ }^{64}$ y, sobre todo, de Sebastian Le Prestre, Conde de Vauban - quien aplicaria en la práctica las teorias de Pagan-, cuyos sistemas se explican ampliamente en ellos en calidad de auténticos paradigmas siempre imitables ${ }^{65}$.

\section{LAS ILUSTRACIONES}

La publicación de tratados de fortificación sin láminas, que les ilustren, intercaladas entre sus páginas o al final de la obra, resulta totalmente impensable. El texto y los grabados están siempre muy relacionados entre si, siendo interdependientes. Se suele hacer referencia de contínuo

6. VALlejo, J. M., obra citada, en nota 27

62 Jean Errard de Bar-le-Duc (1554-1610) ha sido considerado como el padre de la fortificación moderna al publicar en 1594 su tratado titulado La fortification rèduite en art et démontrée. Su actividad como ingeniero tuvo lugar durante el reinado de Enrique IV, dirigiendo el cuerpo de ingenieros del rey por designación del ministro Sully. Encargado de la ordenación de las plazas fuertes francesas, y constructor de la ciudadela de Verdun. introdujo en este pais el uso de la fortificación bastionada. Definió con precisión las funciones que el ingeniero militar debia desempeñar: Habia de ser al mismo tiempo soldado y geometra; asumir tanto la defensa como el ataque de las plazas fuertes. y conocer la artilleria. Su sistema defensivo se basa en la defensa de la fortaleza contra los fuegos de enfilada, enmascarando los flancos de los baluartes por medio de una acertada disposición de los lienzos de las murallas, cuyo espesor intento normalizar.

${ }^{63}$ De Ville (1596-1656) publico en 1628 su tratado titulado Fortifications. Su visión teorica es. sobre todo, la plasmación perfecta de su continua actividad práctica bajo el reinado de Luis XIII de Francia, pues asistió a numerosos sitios. Recomendó la adaptación de la fortificación al terreno. También publicó De la charge des Gouverneurs des Places en 1639

${ }_{64}$ Blaise François de Pagan, Comte de Mervéilles y de Pagan (1604-1665) es, en realidad. el autentico inventor de los tres sistemas defensivos de Vauban, que éste llevó a la practica y perfeccionó, adaptandoles a las circunstancias. Ingeniero militar y Mariscal de Campo, en 1643 perdio la vista debido a una serie de heridas. Desde entonces cambio su actividad eminentemente practica por el quehacer teórico, publicando en Paris en 1645 su Traite des Fortifications (B. N.: 3/45,195) y en 1647 el Traite des planètes. Ideo el escalonamiento de la defensa en profundidad, organizando los "caminos-cubiertos" en el exterior y los baluartes.

is Sebastian Le Preste (1638-1715), Conde de Vauban, recibio el titulo de ingeniero del rey en 1655. Mariscal, despues de pasar por todas las escaias militares y de ejercer en el campo de batalla, su actividad esta relacionada con la politica exterior y militar de Luis XIV. Su idea de fortificación se basa en los conceptos de defensa y de disuación. Escribió en 1669 y en 1705 Traité de l'attaque des places. Traité sur la defense des places y la Fortification de campagne. Sobre Vauban: PARENT, M., Vauban un encyclopediste avant la lettre. (Paris). Berger-Levrault, (1982). 
a las distintas ilustraciones, que sirven al mismo tiempo de objeto y de instrumentos imprescindibles del libro, bien en los márgenes bien entrelíneas de la parte escrita.

Tales grabados ofrecen una gran variedad de figuras geométricas, de modelos de los distintos sistemas de fortificación, de esquemas de problemas útiles para trazar líneas concretas de las diversas partes de las plazas en la consideración de una serie de peculiaridades topográficas y del uso de unos materiales especificos... Se representan también obras ingenieriles, militares y arquitectónicas: puentes, arsenales, dársenas, trincheras, polvorines, planos, alzados y fachadas de cuarteles, hospitales, de iglesias y cementerios fortificados... Al ser las plazas fuertes complejos núcleos urbanos, se aportan, asimismo, planos de ciudades, en donde se distribuyen, por lo general, de una forma reticular, racional y metódica los distintos trazados viarios, las calles y plazas, y el lugar que ocupan en ellas los principales edificios civiles y militares. Asi, estas láminas muestran imágenes prácticas, modelos siempre imitables, en la consideración del pasado y del presente de una compleja arquitectura ingenieril y militar.

Pauner fue un grabador -o un taller familiar, especializado en estos libros de fortificación- que hizo en Barcelona las láminas tanto de la traducción española del tratado de Muller de 1769, como de los libros de Lucuce de 1772 y de March de 1781, estando, al parecer, vinculado artísticamente con la Real Academia Militar de Matemáticas de la ciudad condal ${ }^{66}$. Pero, la serie con la firma de Domingo Pauner, sin duda, más importante de estas tres obras es la del Tratado de fortificación que Miguel Sánchez Taramas tradujo del ingiés, y al que se dedicará aquí una atención especial por su interés.

E6 En el taller barcelones de Pauner se grabaron los tratados de Pedro de Lucuce, Muller y March. Debio ser uno de los talleres familiares más importantes de Cataluña durante la segundad mitad del siglo XVIII. Uno de sus miembros más destacados fue Domingo (Barcelona, 1720-1783), Vid.: CARRETE et alii. Estampas. Cinco siglos de imagen impresa. Madrid. 1981. Tambien se cita a Pauner en: PAEz RIOS. Elena: Repertorio de grabadores españoles en la Biblioteca Nacional, por... (Madrid), Secretaria Técnica de la Dirección General de Bellas Artes, Archivos y Bibliotecas del Ministerio de Cultura, 1982, tomo II, págs. 375-376. La autora de este repertorio dice que Domingo fue un grabador xilográfico natural de Barcelona, que hizo numerosas obras entre 1720 y 1783 . Además de estos tratados de fortificación ilustró una plancha que ocupa la mitad de la portada de la obra de Fray Manuel Mariano Ribera sobre el Celeste Real Patronato... de el real y militar orden de nuestra Señora de la Merced. Redención de Cautivos. Barcelona, 1725. Asimismo ilustro los Exercicios espirituales en el camino de la perfeccion del B. P. S. Ignacio de Loyola. Fundador de la Compañia de Jesús. Barcelona. Pablo Nadal, 1746. A él se le debe un retrato de Fernando $\mathrm{VI}$. 
Este libro ofrece una gran cantidad de ilustraciones en sus dos volúmenes. El traductor e ingeniero militar añadió veintidós láminas (del 1.A al 22.A) a las 26 originales del texto de Muller con numeración romana, que sirven para aclarar algunos pasajes oscuros del inglés 0 , sobre todo, para ofrecer a nuestros oficiales modelos españoles de obras realizadas en su época como alternativa hispánica. De esta forma la parte gráfica del trabajo inglés se amplió considerablemente, ganando importancia a un nivel nacional. Las láminas que se distribuyen de una forma uniforme intercadas a lo largo de los dos volúmentes y que incluyen con un sentido muy didáctico leyendas aclaratorias, están, tal y como es obvio, en función estrecha de los distintos temas tratados en el libro. Se pueden distinguir, asi pues, dos tipos de ilustraciones: las del texto de Muller y las que Sánchez Taramas incorporó para visualizar plásticamente sus propias notas al original inglés. Éstas llevan una numeración distinta arábiga.

Las cinco primeras, que sirven a la parte escrita por Mulier, representan por medio de numerosas figuras dibujos de problemas sobre el espesor de los muros de un parapeto y de los arcos, asi como acerca de la resistencia de un madero. Las siete láminas comprendidas entre la VI y la XII se ocupan del trazado de las fortalezas y de sus distintas partes. De esta forma, y siempre siguiendo al autor, el ingeniero militar podía hallar imágenes útiles para calcular la excavación de los fosos, para trazar el plano de una fortaleza, los muros de fortificación y sus cimientos... La poterna -o paso subterráneo que conduce de las obras interiores a las exteriores de una fortaleza - en sus dos modalidades con escaleras o en declivio- y la caponera -o paso construido en los fosos secos para la comunicación segura de unas obras a otras- son representadas de perfil y en planta. Además de ofrecer modelos de reductos en los rebellines y contraescarpas con casamatas, se proporcionan tres tipos de puertas para las fortalezas en función de la mayor o menor complejidad de su trazado.

Este mismo carácter práctico presentan las láminas numeradas de la XIII a la XXIII. Se ofrecen en ellas una gran variedad de obras y edificios militares: plano y elevación de un cuerpo de guardia, puentes de madera fijos y levadizos, rastrillos, polvorines, plano y perfil de un cuartel tal y como entonces se construian en Inglaterra, tipos de ensamblajes o entramados para muros de división, cabezales, viguetas, armaduras... La lámina XVI tiene un gran interés, pues proporciona el plano de una ciudad fortificada, en el que se indica la distribución de sus calles, plaza principal y casas más destacadas, como las comunes y del gobernador. También se especifican en ellas los lugares que ocuparian la iglesia mayor, los 
cuarteles, almacenes y pabellones, destacandose sus puertas, campos de guardias, puentes de comunicación, estables y levadizos, rampas en los terraplenes y revellines. Caponeras y escaleras para uso del camino cubierto. Hay en el volumen II más láminas, que ilustran las notas añadidas por Sánchez Taramas, que las dedicadas al texto original de $\mathrm{Mu}-$ ller. Éstas tan sólo son tres y reproducen planos y alzados de un puente, de unos muelles de piedra y de madera y de una inclusa.

De las veintidós láminas que Sánchez Taramas publicó para ilustrar sus notas y adiciones, tan sólo siete se incluyeron en el tomo primero. Unas pocas aclaran el texto del inglés como alternativa. Asi, proporciona modelos de puentes de madera según Palladio. Pero lo más original son las reproducciones de obras españolas de la época, grabadas por Pauner y comentadas más o menos extensamente por el ingeniero militar español.

En el tomo I predominan los planos y alzados de cuarteles españoles intercalados después del proporcionado por el autor según se construian entonces ordinariamente en Inglaterra. Ilustran una adición de Sánchez Taramas, en la que ponia en duda la utilidad del modelo publicado por Muller, quien, siguiendo a Belidor, prefería los cuarteles construidos con un gran patio en medio, útiles para fortalezas pequeñas. Su crítica estaba basada en el hecho mismo de necesitar esta disposición la cuarta parte de la totalidad del edificio para construir sólamente las escaleras, asi como en la multitud de puertas para el uso de las tropas, lo cual impedía su recogimiento. A.demás este prototipo no se acomodaba ya al Real Decreto de 14 de octubre de 1766, que disponía una cama por hombre, pues obligaba a levantar, por lo menos, doce habitaciones, y la construcción de las cocinas y comunes separadas del cuerpo de los cuarteles incomodaba a los soldados. Como alternativa proponía el modelo de los cuarteles de Infanteria edificados entonces en el arrabal de la Barceloneta (Láms. 3.A, 4.A y 5.A), así como el del Escuadrón de Caballería y Dragones de Reus (Tarragona) (Láms. 6.A y 7.A).

Sánchez Taramas también publicó a continuación de los planos y alzados de los almacenes de pólvora aportados por el texto de Muller, el plano y perfil cortado de los construidos en la plaza de San Fernando de Figueras con cubiertas góticas o apuntadas.

Otra alternativa al tratado inglés son los modelos de puentes españoles reproducidos por nuestro ingeniero militar y Pauner en el tomo $\|$ y que reflejan tres momentos históricos distintos: el romano con los de Martorell sobre el río Llobregat y de Alcántara sobre el Tajo; el renacentista del puente de Almaraz o de Alvalat sobre ese mismo cauce del año 1552 y los contemporáneos al autor de tales notas. De entre éstos des- 
taca el grabado de la copia del plano, perfil y elevación del Puente Real del Jarama de Aranjuez, construido en 1760 por el comisario de Guerra Marcos de Vierna. En la reproducción no se incluyeron los cuatro leones que sobre las pilastras sostienen los dos escudos de Armas Reales y las dos inscripciones.

El Real Decreto de Carlos III de 10 de junio de 1761 daba una serie de reglas sobre los caminos públicos de todo el reino, que se ocupaban también de los puentes. En este sentido se debió construir el del río Llobregat en las inmediaciones de la Villa de Molins del Rey, que se comenzó a edificar en octubre de 1763 concluyéndose en octubre de 1767 con una longitud de 1,200 pies y una altura de otros 42 sobre quince arcos. La nota y las láminas sobre puentes incorporados por Sánchez Taramas hizo escribir a un anónimo lector con letra del siglo XVIII en el margen de uno de los ejemplares conservados en la Biblioteca Nacional lo siguiente: "Este capitulo del traductor vale más que quanto dice Muller. Con él sólo basta para instruirse bien sobre este punto. El Sr. Muller me parece algo superficial y, y su obra sin las notas del traductor no son cosa muy grande" ${ }^{67}$

Miguel Sánchez Taramas intercaló detrás de la lámina al texto de Muller, que reproduce los perfiles y planos de un muelle de piedra y de madera, una serie de construcciones realizadas en el muelle y en la dársena del arsenal de Cartagena: dos diques de carena con su poza para desaguarlos, dos gradas de construcción y un arrastrero para maderas (láms. 16.A, 17.A y 18. A). En su adición citó los muelles nuevos de piedra de los puertos de Barcelona y Málaga, y se refirió a las obras ejecutadas dentro y fuera del agua en los Reales Arsenales de Marina establecidos en el Ferrol, Cádiz y Cartagena: dársenas, varaderos o gradas de construcción, diques, almacenes generales, de municiones, víveres y pertrechos, cuarteles, pabellones... A lo que añadiría: "Serían necesarios algunos volúmenes para describir con puntualidad la forma, y construcción de todos los Edificios, que contienen los tres Arsenales referidos: lo que, sin embargo, convendria mucho se emprendiese por alguna persona inteligente, para la instrucción de los estudiosos, y beneficio del público" ${ }^{68}$.

La navegación de los ríos y canales fueron ampliamente tratados por este ingeniero militar extremeño, quien, además de reproducir balsas de-

${ }^{67}$ Muller, J., obra citada, vol. II, pág. 93 del ejemplar de la Biblioteca Nacional: 3/ 45,242-3.

68 Ibidem, vol. Il pág. 140. 

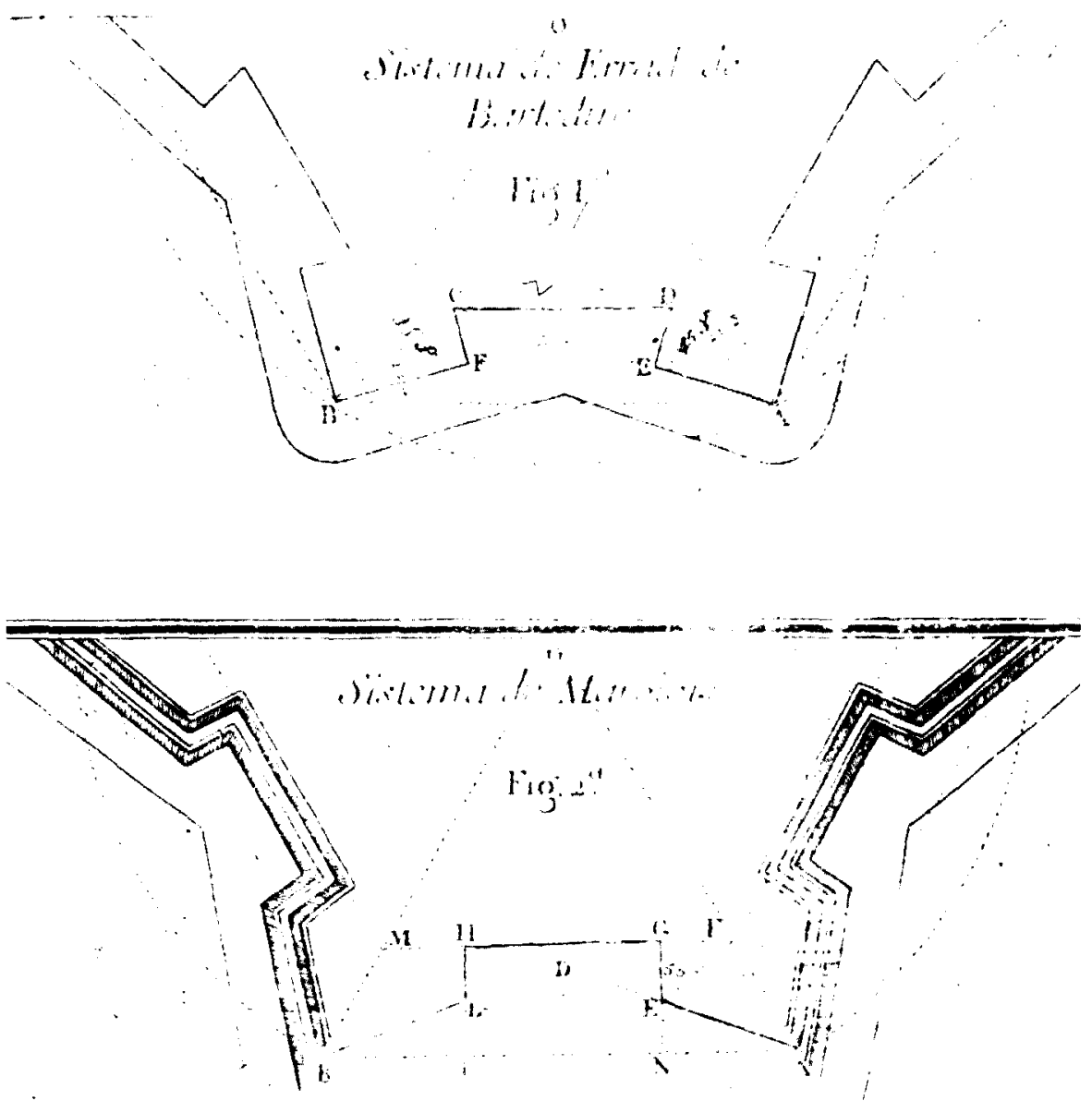

Lamina 17. Lámina 14 de los Elementos de fortificacion de Le Blond. Sistemas de fortificación de Errard de Bar-le-Duc (Fig. 1) y de Marolois (Fig. 2).

siguales y continuas con sus inclusas para embarcaciones grandes y pequeñas, publicó un mapa del proyecto general de canales de navegación y de riego, que entonces se construian en el Reino de Castilla. Los canales de Castilla y de León, que se iniciaron en 1753 durante el reinado de Fernando VI, continuándose con Carlos III, fueron diseñados por el teniente coronel de Infantería e ingeniero en segundo Fernando de Ulloa. También reprodujo el plano, perfiles de dos balsas enfiladas, con sus inclusas, puente de comunicación, acueducto y desagüe que de estos edificios se hallan en el proyecto de dicho canal asi como de la presa 


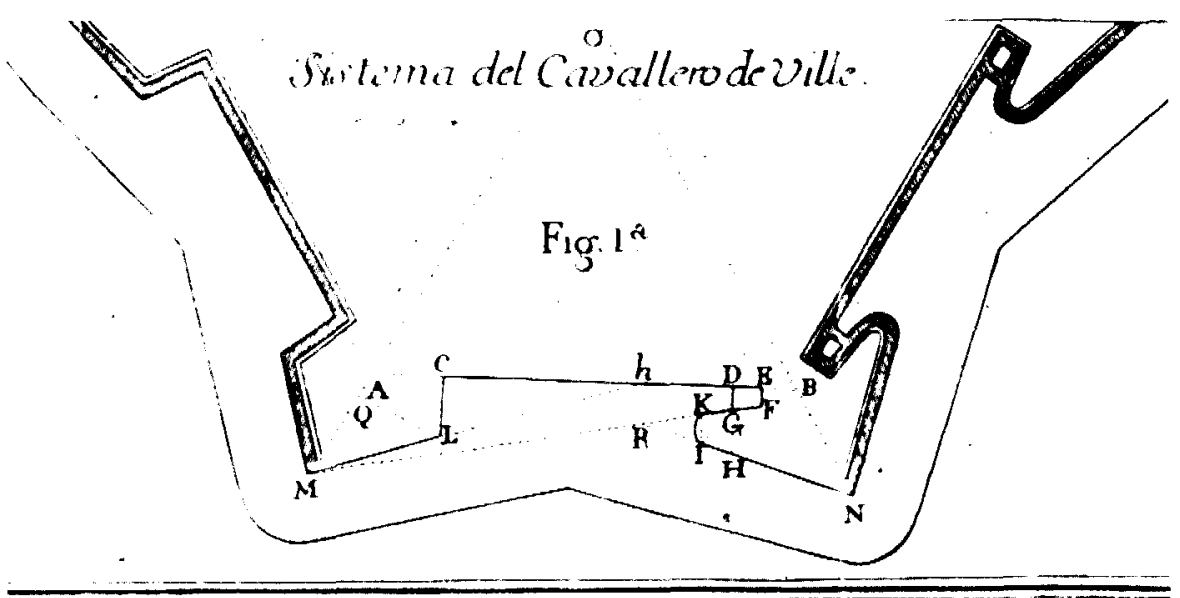

Sistimua del cride dipagan

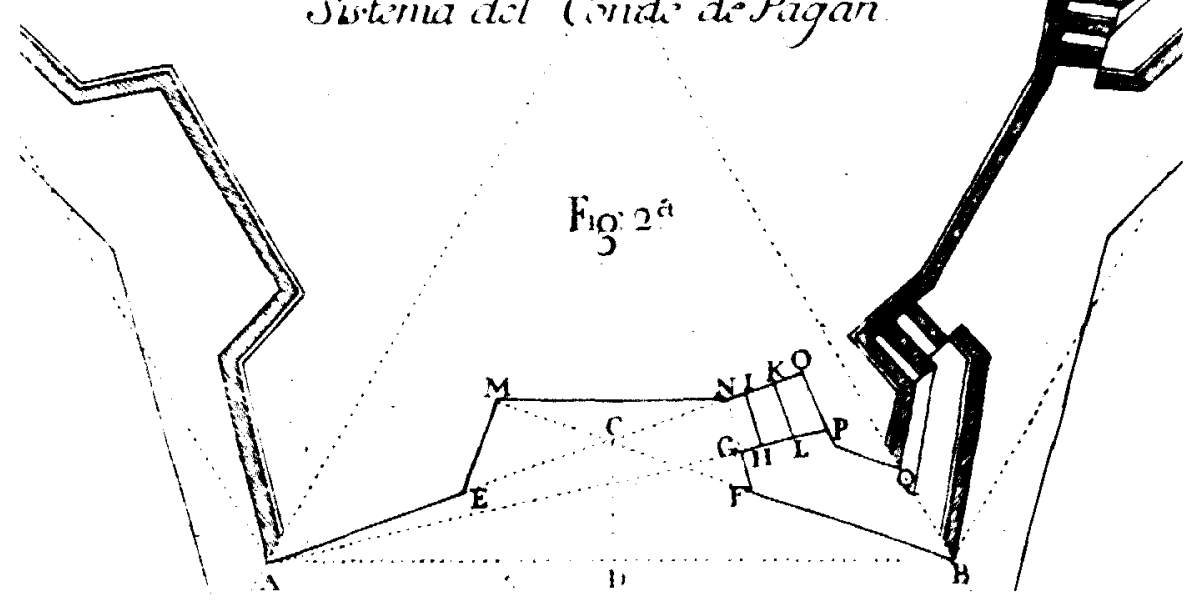

Lámina 18. Lámina 15 de los Elementos de fortificación de Le Blond. Sistemas de fortificación del Caballero De Ville (Fig. 1) y del Conde de Pagan (Fig. 2).

construida en el río Pisuerga, en el paraje donde se cruza el canal junto a la ermita de San Andrés. Se refirió, asímismo a los trabajos que entonces se realizaban para hacer navegables los ríos Ebro y Guadalquivir ${ }^{69}$.

Las diez láminas plegadas, también grabadas por Pauner, de los Principios de fortificación de Pedro de Lucuce, publicados en 1772, tienen un carácter muy distinto. Estas ilustraciones poseen menos calidad artís-

69 Ibidem, vol. II, págs. 252-253. 

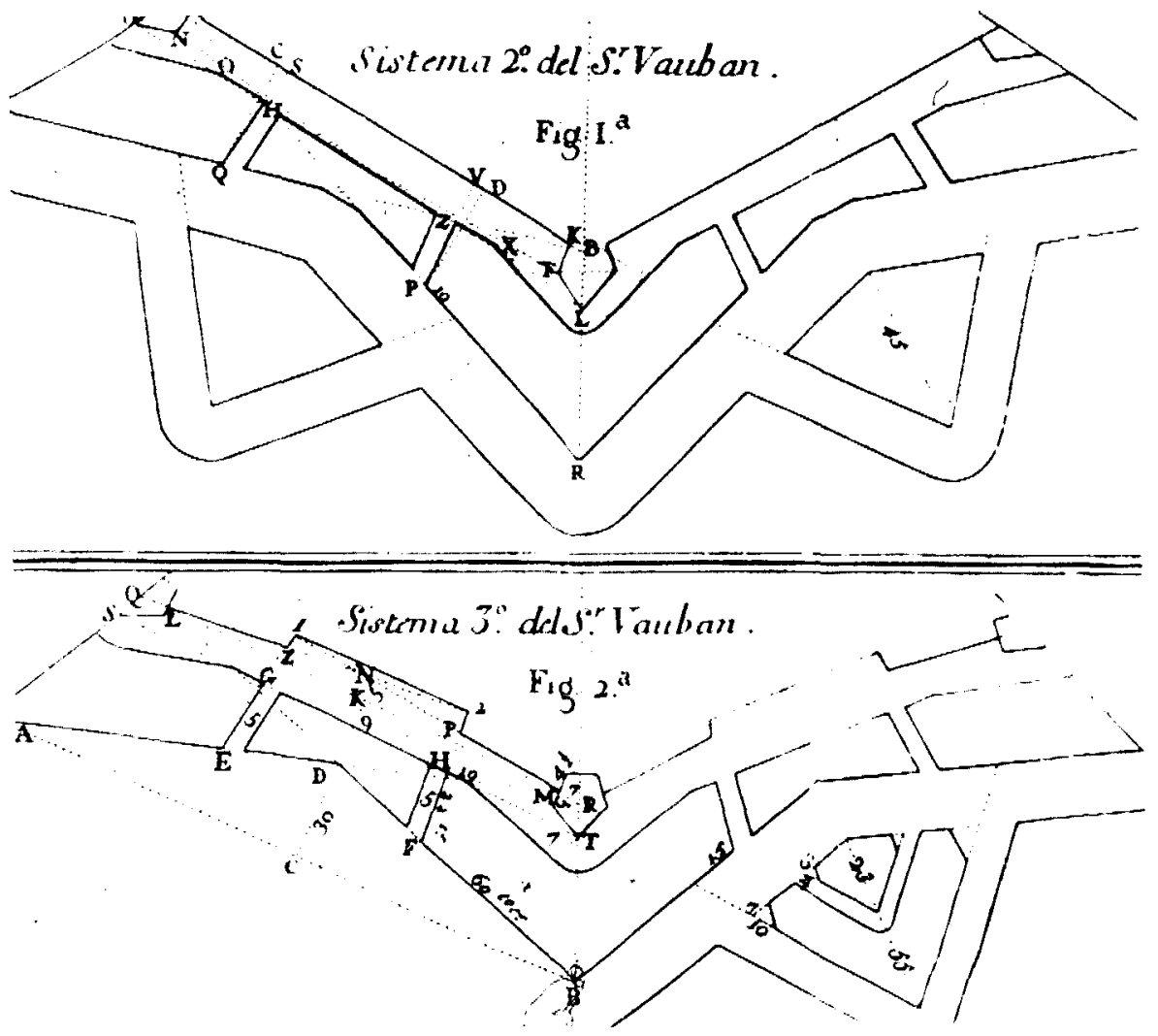

Lámina 19. Lámina 16 de los Elementos de fortificación de Le Blond. Sistemas 2. ${ }^{\circ}$ (Fig. 1) y $3 .^{\circ}$ (Fig. 2) de Vauban.

tica e interés para el estudio histórico de los edificios militares y obras ingenieriles que el tratado de Muller. Su importancia gráfica es, sobre todo, pedagógica al acomodarse con toda fidelidad y pragmatismo al texto. Sirven didácticamente para aprender a trazar las distintas líneas de una plaza fortificada, así como trincheras, y proporcionan imágenes de los pertrechos necesarios para la construcción de obras de campaña: cestón, fagina, manteletes, blinda, pilote, zarzo, candelero... El tratado es, asimismo, útil para visualizar planos sobre líneas de ataque a una plaza fortificada y la colocación de las baterías. 


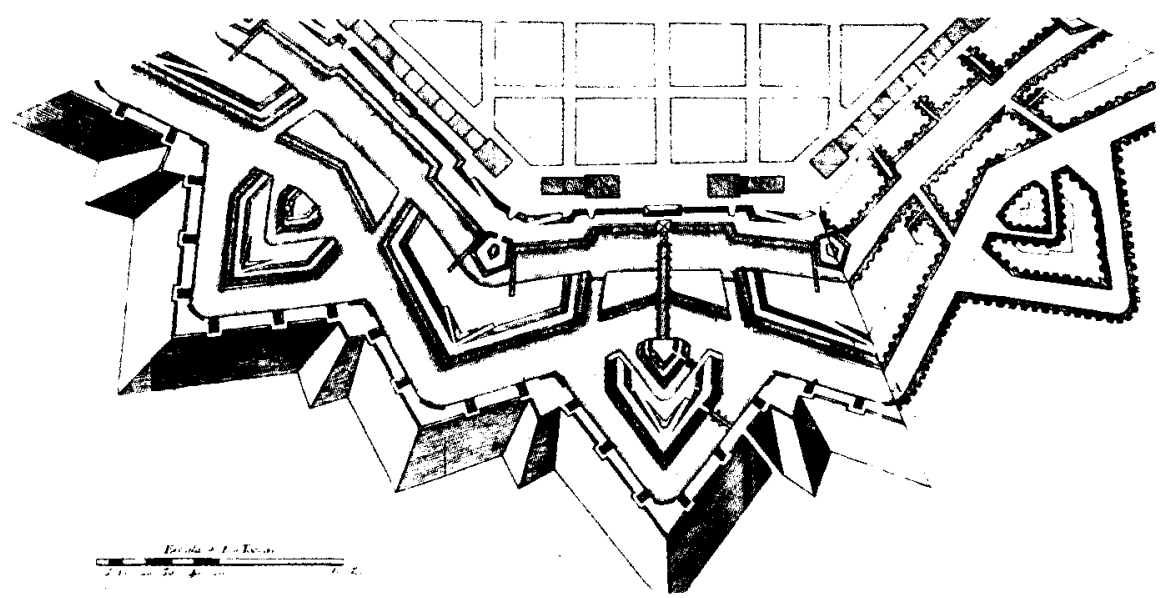

Lamina 20. Lámina 17 de los Elementos de fortificación de Le Blond. Plano de una fortaleza con subterráneos, mampostería de los revestimientos, contrafuertes...

Estas láminas, que incorporan numerosas figuras numeradas correlativamente, se hallan al final del libro, detrás del texto. Sus trazos suelen ser bastante más esquemáticos que los de la traducción castellana de esa obra inglesa. Por los temas incorporados están en una línea muy parecida a las que ilustran la edición española de 1776 de los Elementos de fortificación de Le Blond, cuyos grabados fueron hechos por Manuel Rodríguez. Carecen, por lo general, de leyendas aclaratorias, salvo alguna excepción, por lo cual se necesita la lectura minuciosa del texto para entenderlas correctamente.

Los grabados del libro de Lucuce con sus dibujos muy técnicos se especializan, sobre todo, en el trazado de distintas partes de una plaza fortificada, introduciéndose con una serie de figuras geométricas. El exágono elemental y el medio exágono son objeto de representación fortificada, indicándose sus diferentes lineas: flanco curvo retirado, tenazón simple y doble rebellín sencillo, con flancos y doble o cortado, medialuna, contraguardia... También se reproducen aquí variedades de tenazas y hornabeques, así como otros elementos de la fortificación: garitas, rastrillos, reductos, abrojos, espinas, molinillos, puerco espín... Una de sus láminas más bellas es, sin duda, la dedicada a la plaza fortificada con su ciudadela, en la que se indican todas sus obras principales.

Pauner también grabó en Barcelona en 1781 las ocho láminas muy apaisadas de que constan las Nociones militares de Joseph Ignacio 
March, publicadas como un suplemento a los principios de fortificación de Lucuce. Sus ilustraciones se hallan en esa misma línea, si bien en ellas se cargan las tintas sobre la representación de las figuras geométricas, a las que se dedican las tres primeras láminas con más de 125 dibujos en total. En realidad, son modelos que sirven para trazar dichas figuras a partir de una recta dada, aunque se aportan, asímismo, una serie de ilustraciones útiles para poder medir las distancias y las alturas accesibles e inaccesibles, y de instrumentos, como el llamado nivel de agua, que se usaba comúnmente para nivelar el terreno.

Las láminas IV, V, VI y VII del libro de March están dedicadas a los reductos, existiendo, tal y como casi siempre suele ocurrir en estos libros, una relación didáctica muy extrecha entre el texto y los grabados. En ellas se representan tanto su diferente tipología como las preparaciones más oportunas para construirlos y el modo de trazarlos, la colocación de obstáculos para su defensa y una aplicación minuciosa de la perspectiva de un reducto cuadrado. Las numerosas figuras se publican aqui numeradas correlativamente con independencia de las dedicadas a la Geometría.

José Ignacio March proporcionó cuatro tipos de esta especie de fuerte cerrado por todas partes, que consta principalmente de foso, parapeto y banqueta. En el texto indicó las ventajas y los inconvenientes de cada uno de ellos. Así, los más defectuosos eran según su opinión el baluarte de forma cuadrada, porque en cada ángulo deja un espacio de un sector de circulo de $90^{\circ}$, y el reducto octogonal, ya que en sus ángulos quedaban muchos espacios sin defensa del fuego. El circular le parecía más oportuno, pues podía extenderse el fuego con igualdad por todas las partes, y el reducto cuadrado de forma de dientes de sierra lo pensaba como el más perfecto de todos ellos.

March incluyó en la lámina VI diez figuras, en las que proporcionaba una serie de modelos sobre la forma de colocación de las estacadas o palizadas en función de su grado de inclinación de $45^{\circ}$, perpendicular y horizontal, pozos de construcción cónica, árboles y demás obstáculos, que conducen a la mayor defensa de los reductos. Estos son representados en un plano y en perspectiva, con la minuciosa señalización de sus diversas partes: centro y espacio interior de un reducto, banqueta, declivio, berma, escarpa, foso, contraescarpa, empalizada... En el plano se indica el emplazamiento que deben ocupar todos los obstáculos defensivos. Las ilustraciones de Pauner aportan, asímismo, modeios para la fortificación de una casa, de las estacas y troneras, y del ariete antiguo. 
La forma de defender los cementerios y corrales, el doble recinto y la de una localidad, en la que se cerca todo con cortaduras en las calles y colocación de palizadas, así como de otro lugar compuesto por casas sueltas separadas por distancias diferentes sin formar calle alguna se indica en la lámina VII. La última está dedicada a las marchas con el orden y precaución que debe tomar todo destacamento.

En los Elementos de Fortificación de Le Blond, publicados en 1776 y reimpresos ya en 1805, tan sólo la lámina 17 de entre las 22 incluidas está firmada por "Ml. Rodrigz. fc.". Obra dedicada exclusivamente a la fortificación y dividida en cuatro secciones, se refiere tanto a la regular como a la irregular. En la tercera parte se ocupa de los principales sistemas, que reproduce gráficamente. Se representan, así, en cuatro láminas los esquemas de los métodos de fortificación de Errard de Bar-leDuc (ingeniero de Enrique IV y el primero entre los franceses que concibió un tratado de fortificación en 1594 por encargo de Sully, Ministro y superintendente de las fortificaciones), de Marolois, llamado el sistema holandés, del Caballero De Ville (ingeniero de la época del rey Luis XIII, quien publicó otro tratado sobre esta displicina en 1629), del Conde de Pagan (Mariscal de Campo, quien en 1645 dio a la imprenta un texto) y del Mariscal Vauban.

La mayoría de las ilustraciones de este tratado se dedican a la delineación de las plazas fortificadas y de sus distintas partes y líneas en la consideración de sus diversas clases: baluartes, contraescarpa, foso, tenazón, caponera, terraplén, camino cubierto, esplanada, revellín, contraguardia, lunetas, reductos, hornaveques, flechas... La edición española incluye varios planos y perfiles, indicándose métodos para trazar las calles de la regular, plaza de armas cuadrada, cuarteles, pabellones para oficiales... También se dedican varios grabados a las cañoneras y a la defensa del recinto fortificado, a la ciudadela, a los reductos y a los sistemas para fortificar todo tipo de polígonos, triángulos, cuadrados y otras figuras irregulares.

Manuel Rodríguez también firmó con sus iniciales las cinco láminas incluidas en el Tratado de defensa de las plazas de Le-Blond. La primera de ellas proporciona tres figuras dedicadas a las contraminas de una luneta, un reducto y un baluarte. En las otras cuatro se reproducen planos de defensas históricas. Así, en la II se publica el campo atrincherado delante de Dunkerque, realizado en 1706 por el Mariscal Vauban entre los canales de la Macre y de Burgurgo y el fuerte Luis, y en la III se muestra el campo atrincherado de Schellemberg junto al río Danubio y Donawert. La lámina IV incluye el plano de la mina hecha en La Fere el 27 de septiembre de 1739 para volar hacia la plaza la artillería estable- 
cida sobre la cresta del camino cubierto, mientras que la $V$ aporta el perfil de un nuevo proyecto de minas hecho también en esa plaza para volar, asismismo, hacia plaza la artillería del sitiador establecida sobre el camino cubierto. 
